\title{
Inferences of mantle viscosity based on ice age data sets: Radial structure
}

\section{Citation}

Lau, Harriet C. P., Jerry X. Mitrovica, Jacqueline Austermann, Ophelia Crawford, David Al-Attar, and Konstantin Latychev. 2016. "Inferences of Mantle Viscosity Based on Ice Age Data Sets:

Radial Structure." Journal of Geophysical Research: Solid Earth 121 (10): 6991-7012. https:// doi.org/10.1002/2016jb013043.

\section{Permanent link}

http://nrs.harvard.edu/urn-3:HUL.InstRepos:41401426

\section{Terms of Use}

This article was downloaded from Harvard University's DASH repository, and is made available under the terms and conditions applicable to Other Posted Material, as set forth at http:// nrs.harvard.edu/urn-3:HUL.InstRepos:dash.current.terms-of-use\#LAA

\section{Share Your Story}

The Harvard community has made this article openly available.

Please share how this access benefits you. Submit a story.

Accessibility 


\section{Journal of Geophysical Research: Solid Earth}

\section{RESEARCH ARTICLE \\ 10.1002/2016JB013043 \\ Inferences of mantle viscosity based on ice age data sets: Radial structure}

Key Points:

- The radial profile of mantle viscosity is inferred from a formal, nonlinear inversion of an updated glacial isostatic adjustment data set - The viscosity increases significantly with depth, with a deep mantle value constrained by the $J_{2}$ datum after correction for modern melting - GIA data can accommodate a viscosity jump in the lower mantle (in the depth range $1000-1700 \mathrm{~km}$ ) of 1-2 orders of magnitude

Correspondence to:

H. C. P. Lau,

harrietlau@fas.harvard.edu

\section{Citation:}

Lau, H. C. P., J. X. Mitrovica,

J. Austermann, O. Crawford,

D. Al-Attar, and K. Latychev (2016),

Inferences of mantle viscosity based

on ice age data sets: Radial structure,

J. Geophys. Res. Solid Earth,

121, 6991-7012,

doi:10.1002/2016JB013043.

Received 31 MAR 2016 Accepted 14 SEP 2016 Accepted article online 19 SEP 2016 Published online 9 OCT 2016

(2016. American Geophysical Union. All Rights Reserved.

\author{
Harriet C. P. Lau ${ }^{1}$, Jerry X. Mitrovica ${ }^{1}$, Jacqueline Austermann ${ }^{1}$, Ophelia Crawford ${ }^{2}$, David Al-Attar ${ }^{2}$, \\ and Konstantin Latychev ${ }^{3}$ \\ ${ }^{1}$ Department of Earth and Planetary Sciences, Harvard University, Cambridge, Massachusetts, USA, ${ }^{2}$ Bullard Laboratories, \\ Department of Earth Sciences, University of Cambridge, Cambridge, UK, ${ }^{3}$ Department of Physics, University of Toronto, \\ Toronto, Ontario, Canada
}

Abstract We perform joint nonlinear inversions of glacial isostatic adjustment (GIA) data, including the following: postglacial decay times in Canada and Scandinavia, the Fennoscandian relaxation spectrum (FRS), late-Holocene differential sea level (DSL) highstands (based on recent compilations of Australian sea level histories), and the rate of change of the degree 2 zonal harmonic of the geopotential, $J_{2}$. Resolving power analyses demonstrate the following: (1) the FRS constrains mean upper mantle viscosity to be $\sim 3 \times 10^{20} \mathrm{~Pa} \mathrm{~s}$, (2) postglacial decay time data require the average viscosity in the top $\sim 1500 \mathrm{~km}$ of the mantle to be $10^{21} \mathrm{~Pa} \mathrm{~s}$, and (3) the $J_{2}$ datum constrains mean lower mantle viscosity to be $\sim 5 \times 10^{21} \mathrm{~Pa}$ s. To reconcile (2) and (3), viscosity must increase to $10^{22}-10^{23} \mathrm{~Pa}$ s in the deep mantle. Our analysis highlights the importance of accurately correcting the $J_{2}$ observation for modern glacier melting in order to robustly infer deep mantle viscosity. We also perform a large series of forward calculations to investigate the compatibility of the GIA data sets with a viscosity jump within the lower mantle, as suggested by geodynamic and seismic studies, and conclude that the GIA data may accommodate a sharp jump of 1-2 orders of magnitude in viscosity across a boundary placed in a depth range of 1000-1700 km but does not require such a feature. Finally, we find that no 1-D viscosity profile appears capable of simultaneously reconciling the DSL highstand data and suggest that this discord is likely due to laterally heterogeneous mantle viscosity, an issue we explore in a companion study.

\section{Introduction}

The viscosity structure of the Earth's mantle, as inferred from data related to glacial isostatic adjustment (hereafter GIA), has been a source of debate spanning decades, with consensus oscillating between arguments for a significant increase in (spherically averaged) viscosity with depth from the base of the lithosphere to the deep mantle [e.g., McConnell, 1968; O'Connell, 1971], to suggestions of an essentially isoviscous mantle [e.g., Cathles, 1975; Peltier, 1976; Wu and Peltier, 1983, 1984; Tushingham and Peltier, 1992] and back again [e.g., Nakada and Lambeck, 1989; Mitrovica, 1996]. The latter studies were broadly consistent with independent inferences based on viscous flow modeling of surface observables associated with mantle convection [e.g., Ricard et al., 1984; Richards and Hager, 1984; Forte, 1987; Hager and Richards, 1989; King and Masters, 1992], which favor viscosity profiles that increase 1-2 orders of magnitude from the base of the lithosphere to the core-mantle boundary (CMB). This apparent reconciliation weakened arguments for a transient (i.e., time-scale dependent) mantle viscosity [Sabadini et al., 1985; Peltier et al., 1986] and was supported by two other lines of study. First, joint inversions of data associated with GIA and mantle convection yielded simultaneous fits to both data sets and viscosity profiles that were characterized by a significant (several order of magnitude) increase of viscosity with depth [Forte and Mitrovica, 1996; Mitrovica and Forte, 1997, 2004; Kaufmann and Lambeck, 2002]. Second, a reanalysis of GIA-based inferences of an isoviscous mantle demonstrated that many such studies had misinterpreted the so-called Haskell number (1021 Pa s) [Haskell, 1935] as a constraint on the bulk average viscosity above $670 \mathrm{~km}$ depth (the modern definition of the upper mantle) rather than the average above $\sim 1200 \mathrm{~km}$ depth, as indicated by a resolving power analysis of the Fennoscandian sea level record that the Haskell number was based upon [Mitrovica, 1996]. This misinterpretation biased these inferences toward a lower mantle viscosity of $10^{21} \mathrm{~Pa} s$ and isoviscous mantle models. However, while more recent GIA-based estimates of mantle viscosity are no longer tied to bulk upper mantle values of $10^{21}$ Pa s [Peltier, 2004], there remain significant apparent differences between such inferences, 
particularly within the lower mantle [e.g., Argus et al., 2014; Nakada et al., 2015a], where discrepancies continue to exceed an order of magnitude. One goal of the present study is to understand the origin of these differences.

A major complication in GIA-based studies of mantle viscosity is the strong sensitivity of most ice age-related observations to the space-time history of ice cover, and the most rigorous analyses have sought parameterizations of the data that reduce this sensitivity. These parameterizations include the strandline-derived Fennoscandian relaxation spectrum (FRS) [e.g., McConnell, 1968; Mitrovica and Peltier, 1993a; Wieczerkowski et al., 1999; Peltier, 2004], relaxation times estimated from the postglacial uplift of previously glaciated regions [e.g., Mitrovica and Peltier, 1995, 1996; Mitrovica and Forte, 1997; Peltier, 1998a; Mitrovica et al., 2000; Nordman et al., 2015], and differential late Holocene sea level highstands from sites in the far field of ice cover [Nakada and Lambeck, 1989]. Resolving power analyses indicates that the FRS and postglacial decay times from Fennoscandia are sensitive to viscosity variations to a depth of $\sim 1200 \mathrm{~km}$ [Parsons, 1972; Mitrovica and Peltier, 1993a; Mitrovica, 1996], while decay times from Hudson Bay, a region covered by the massive Laurentide Ice Sheet, are sensitive to viscosity to a depth of $\sim 1600 \mathrm{~km}$ [Mitrovica, 1996]. As a consequence, analyses based upon these data sets do not constrain viscosity in the bottom half of the mantle [e.g., McConnell, 1968; Mitrovica and Peltier, 1993a, 1995; Mitrovica, 1996; Peltier, 1998a; Wieczerkowski et al., 1999]. One way to extend the sensitivity to the $\mathrm{CMB}$ is to augment the analysis with long-wavelength observables related to mantle convection [Forte and Mitrovica, 1996; Mitrovica and Forte, 1997, 2004]. Differential sea level highstands, since they reflect, in part, the response to large-scale ocean loading [Nakada and Lambeck, 1989], have a nonzero sensitivity to viscosity that extends to the $\mathrm{CMB}$; however, these data are also sensitive to shallower, upper mantle structure [Kendall and Mitrovica, 2007].

In the 1980s and 1990s, a number of GIA analyses incorporated satellite-derived estimates of the rate of change of low-degree zonal harmonics of the Earth's geopotential into inferences of mantle viscosity and in particular $j_{2}$ [Yoder et al., 1983; Rubincam, 1984; Wu and Peltier, 1984; Peltier, 1985; Yuen and Sabadini, 1985; Mitrovica and Peltier, 1989; Vermeersen et al., 1998]. While this effort stalled with the growing recognition that these harmonics were sensitive to ongoing ice mass variations [e.g., Sabadini et al., 1988; Peltier, 1988; Ivins et al., 1993; Mitrovica and Peltier, 1993a; Peltier, 1998b], the deep mantle sensitivity provided by the $\dot{j}_{2}$ observation [Mitrovica and Peltier, 1993a; Peltier, 1998b; Morrow et al., 2013] has continued to make it a focus of GIA research. In this regard, recent GIA analyses have followed two approaches. In the first, Peltier and colleagues [Peltier, 2004; Argus et al., 2014; Peltier et al., 2014] have used the datum to constrain deep mantle viscosity under the assumption that melting of ice sheets and glaciers had negligible impact on the $\dot{J}_{2}$ signal estimated from the analysis of satellite altimeter records prior to $\sim 1990\left(\sim-3 \times 10^{-11}\right.$ years $\left.{ }^{-1}\right)$. The VM2 and VM5a viscosity profiles (Peltier [2004] and Argus et al. [2014], respectively) are characterized by a deep mantle value of $\sim 3 \times 10^{21}$ Pa s. In contrast, Nakada et al. [2015a] and Mitrovica et al. [2015] infer deep mantle viscosity using the pre-1990 $j_{2}$ datum after correction for an ice melt signal based on a tabulation of glacier mass flux appearing in the Fifth Assessment Report of the Intergovernmental Panel on Climate Change (IPCC) [Vaughan et al., 2013]. Both these studies argued for a deep mantle viscosity in excess of $10^{22} \mathrm{~Pa}$ s.

In this study we return, once more, to the inverse problem for mantle viscosity. In particular, we perform, for the first time, joint nonlinear inversions of GIA data sets, including the FRS, decay times determined from local sea level curves in Fennsocandia and Hudson Bay, differential sea level highstands and $\dot{J}_{2}$. In regard to the last of these, we explore the sensitivity of the inversions to the correction of the pre-1990 trend for the signal due to glacier and ice sheet mass flux. As noted above, one overarching goal is to understand the nature and significance of the major inconsistencies in recently published GIA-based inferences of mantle viscosity [Argus et al., 2014; Peltier et al., 2015; Nakada et al., 2015a]. Specifically, we explore whether these differences are significant given the finite resolving power of the GIA data sets and, if so, whether particular data sets are responsible for the discrepancy. The analysis herein serves as a comprehensive study of the information content in these classical data sets of GIA used to infer the radial profile of mantle viscosity. Discrepancies in the above inferences may arise from lateral heterogeneities in viscoelastic structure. In a companion study we use synthetic calculations of GIA on a 3-D, viscoelastic Earth model to assess the level of bias introduced into our inversions by our neglect of lateral viscosity structure. 


\section{Methodology}

\subsection{The Forward Problem}

We are concerned with four distinct observables: (1) the Fennoscandian relaxation spectrum, (2) decay times from relative sea level (uplift) curves near the center of the ancient Laurentian and Fennoscandian Ice Sheets, (3) $j_{2}$, and (4) differential sea level highstands. In the following, we briefly summarize forward calculations associated with each. All calculations adopt spherically symmetric, (Maxwell) viscoelastic, and self-gravitating Earth models. The elastic and density structure of all models is given by the seismic model preliminary reference Earth model (PREM) [Dziewonski and Anderson, 1981]. Unless otherwise specified, for all calculations that involve a space-time history of ice cover, we adopt the ice model ICE-6G [Argus et al., 2014; Peltier et al., 2015].

\subsubsection{The Relaxation Spectrum}

Following Peltier [1974], viscoelastic load (or tidal effective) Love numbers can be written in the following general, impulse response form

$$
\chi_{\ell}(t)=\chi_{\ell}^{E} \delta(t)+\sum_{n=1}^{N} r_{n}^{\ell} \exp \left(-s_{n}^{\ell} t\right),
$$

where the time-dependent Love number, $\chi_{\ell}(t)$ at spherical harmonic degree $\ell$, is decomposed into an immediate elastic response, $\chi_{\ell}^{E}$, followed by viscoelastic relaxation governed by $N$ normal modes of exponential decay. Each normal mode is prescribed by an amplitude $r_{n}^{\ell}$ and inverse decay time, or eigenfrequency, $s_{n}^{\ell}$, and these are functions of the density, elastic, and viscosity structure of the adopted Earth model [Peltier, 1974; $W u, 1978]$. The collection of $s_{n}^{\ell}$ forms the relaxation spectrum for a given viscoelastic Earth model.

We compute the relaxation spectrum using the approach described by Peltier [1974]. As discussed below, the Fennoscandian relaxation spectrum (FRS) determined from geological records of sea level change is defined by a single, best-fitting decay time at each harmonic degree above 10 in a strandline deformation field. Forward calculations of the relaxation spectrum indicate that above degree 10 , the response is dominated by the fundamental " $\mathrm{MO}$ " mode of relaxation, and synthetic tests indicate that neglecting other modes of relaxation in forward predictions does not introduce significant error into the analysis of the observed spectrum [Wieczerkowski et al., 1999]. As a consequence, in computing the relaxation spectrum we limit ourselves to the fundamental mode, and, for simplicity, we drop the subscript $n$ when referring to the FRS spectrum, $s_{\ell}$.

\subsubsection{Postglacial Decay Times}

Postglacial decay times are computed in two steps. First, we solve the sea level equation derived by [Mitrovica and Milne, 2003] using the pseudo-spectral algorithm outlined in Kendall et al. [2005] with a truncation at spherical harmonic degree and order 256. This gravitationally self-consistent treatment incorporates the migration of shorelines and the signal in sea level due to perturbations in Earth rotation, and it requires, as input, a viscoelastic Earth model and an ice history. Upon output, the calculation yields sea level changes over time at any site $\mathbf{r}$ relative to sea level at present $\left(t_{\mathrm{p}}\right)$, i.e., relative sea level $(\mathrm{RSL})$ :

$$
\mathrm{RSL}(\mathbf{r}, t)=\mathrm{SL}(\mathbf{r}, t)-\mathrm{SL}\left(\mathbf{r}, t_{\mathrm{p}}\right) \text {. }
$$

We note that sea level in this context is defined as the height of the sea surface equipotential, which is globally defined, relative to the solid surface.

It has long been understood that RSL curves at sites near the center of ancient ice sheets (e.g., Hudson Bay) are characterized by an exponential decay given by the form [Walcott, 1972]

$$
\mathrm{RSL}(\mathbf{r}, t) \approx A(\mathbf{r})[\exp \{t / \lambda(\mathbf{r})\}-1]
$$

during periods when no ice remains in the vicinity of the site (i.e., the uplift is in so-called free decay). While the amplitude $A$ is a strong function of both the Earth model and the ice history, the decay time $\lambda$ is much less sensitive to the ice history [e.g., Mitrovica and Peltier, 1995; Mitrovica et al., 2000; Nordman et al., 2015]. Our forward prediction of the postglacial decay time for a specific site $\boldsymbol{r}$ is based on finding the best fit function of the form (3) through the RSL curve calculated using the full sea level theory described above.

2.1.3. $j_{2}$

The coefficient $J_{2}$, the dynamical form factor, is a measure of the oblateness of the Earth's geoid. Specifically, it may be expressed as the suitably normalized spherical harmonic degree 2 and order 0 coefficient in a spherical harmonic decomposition of the geopotential. As noted above, the calculation of gravitationally 
self-consistent sea level changes naturally yields a determination of changes in both bounding surfaces of sea level: the sea surface, which is constrained to remain an equipotential, and the solid surface. The $J_{2}$ coefficient, and its rate of change, $j_{2}$, may then be trivially determined from a time series of the degree 2 zonal harmonic of the sea surface height (or the geoid). Details of this mapping are given in Mitrovica and Peltier [1993a]. Predictions of $j_{2}$ are sensitive to the total change in ice volume from the Last Glacial Maximum to the end of the deglaciation phase but not to the detailed geometry of the ice cover [Wu and Peltier, 1984]

\subsubsection{Differential Sea Level Highstands}

In the far-field of ice cover, relative sea level histories are commonly characterized by a fall in sea level of several meters during the current interglacial. The physics of this sea level fall, which follows the rapid sea level rise associated with the global deglaciation, is well understood [e.g., Nakada and Lambeck, 1989; Mitrovica and Peltier, 1991; Mitrovica and Milne, 2003; Lambeck et al., 2012], and it reflects the combined impact of the following: (1) continental levering, the tilting of the crust at shorelines driven by ocean loading, and (2) ocean syphoning, the migration of water from far-field shorelines to fill accommodation space created by the subsidence of the peripheral bulges that encircle the areas of ancient ice cover and offshore areas experiencing continental levering. The sea level fall produces a RSL highstand that dates to the time when major melting ceased. If the age of the far-field highstand record at site $\mathbf{r}_{1}$ is $t_{1}$ and at site $\mathbf{r}_{2}$ is $t_{2}$, then the differential sea level (DSL) highstand between these two sites is defined as

$$
\mathrm{DSL}_{1,2}=\operatorname{RSL}\left(\mathbf{r}_{2}, t_{2}\right)-\operatorname{RSL}\left(\mathbf{r}_{1}, t_{1}\right) \text {. }
$$

Calculating the DSL for any pair of sites is straightforward using the output of the ice age sea level calculation described in section 2.1.2. By taking the difference of the two sites within reasonably close proximity, it is thought that the dependence on ice history is significantly reduced [Nakada and Lambeck, 1989].

\subsection{The Inverse Problem}

The data considered in this study, the Fennoscandian relaxation spectrum, postglacial decay times, the $j_{2}$ harmonic, and far-field differential sea level highstands, are all nonlinear functions of the radial viscosity profile adopted in the forward calculations. That is, the Fréchet, or sensitivity kernels associated with these data are themselves functions of the viscosity profile. As such, our inversions adopt a nonlinear Bayesian methodology [Tarantola and Valette, 1982; Backus, 1988] in which constraints provided by any observations are combined with an a priori probability distribution to produce an a posteriori estimate of the radial viscosity profile. If we assume that any prior information and observational errors are Gaussian, then the maximum likelihood estimate of the posterior distribution may be found by solving the following iterative algorithm [Tarantola and Valette, 1982]:

$$
\hat{\mathbf{X}}_{k+1}=\hat{\mathbf{X}}_{k}+\left(\mathbf{F}_{k}^{T} \mathbf{V}_{\xi}^{-1} \mathbf{F}_{k}+\mathbf{V}_{\mathbf{P R}}^{-1}\right)^{-1} \times\left\{\mathbf{F}_{k}^{T} \mathbf{V}_{\xi}^{-1}\left(\mathbf{y}-f\left(\hat{\mathbf{X}}_{k}\right)\right)-\mathbf{V}_{\mathrm{PR}}^{-1}\left(\hat{\mathbf{X}}_{k}-\mathbf{X}_{\mathrm{PR}}\right)\right\},
$$

where $\hat{\mathbf{X}}_{k}$ is the $k$ th model iterate, $\mathbf{F}_{k}$ is a matrix whose rows are the discretized form of the Fréchet kernels (i.e., partial derivatives) associated with $\hat{\mathbf{X}}_{k}, \mathbf{V}_{\xi}$ is the covariance matrix of the data errors (with zero mean), $\mathbf{X}_{\mathrm{PR}}$ and $\mathbf{V}_{\mathrm{PR}}$ are the prior model and covariance matrix, $\mathbf{y}$ is the observational data vector, and $f\left(\hat{\mathbf{X}}_{k}\right)$ is a forward prediction of the data vector based on model $\hat{\mathbf{X}}_{k}$. Since the problem is nonlinear, tests must be performed to ensure that the converged solution is not sensitive to the prior or starting model on spatial scales resolved by the data (see below).

Following earlier work [Mitrovica and Peltier, 1995; Mitrovica, 1996; Mitrovica and Forte, 2004], we parameterize the model in terms of the logarithm of the viscosity profile $\log v(r)$, where $r$ is the radius, in some discretized form. In this case, the inverse problem is rendered weakly nonlinear, and the a posteriori covariance matrix of the model, $\mathbf{V}_{\mathrm{PO}}$, may be approximated as [Tarantola and Valette, 1982; Backus, 1988]

$$
\mathbf{V}_{\mathrm{PO}} \approx\left[\mathbf{F}^{T} \mathbf{V}_{\xi}^{-1} \mathbf{F}+\mathbf{V}_{\mathrm{PR}}^{-1}\right]^{-1},
$$

where $\mathbf{F}$ is the matrix of Fréchet kernels computed using the final model iterate. Using the $\log v(r)$ parameterization, we define the Fréchet kernel for a given datum $y_{i}, F_{i}(\log v, r)$, by the relation

$$
\delta \log y_{i}=\int_{\mathrm{CMB}}^{\mathrm{LAB}} F_{i}(\log v, r) \delta \log v(r) r^{2} \mathrm{~d} r,
$$

where $C M B$ and $L A B$ are the radii of the core-mantle boundary and the lithosphere-asthenosphere boundary (or the base of the lithosphere), respectively [Mitrovica and Peltier, 1995]. 
In the case of forward predictions of the relaxation spectrum, Peltier [1976], following Parsons [1972], derived analytical expressions for the kernels $F_{i}$, and we adopt these expressions. For predictions of $j_{2}$, postglacial decay times and DSL highstands, we compute the Fréchet kernels using the numerical perturbation procedure described by Mitrovica and Peltier [1993a]. In this case we discretize the radial viscosity profile (and the Fréchet kernels) into 28 layers, 13 in the upper mantle and 15 in the lower mantle. By choosing a discretization that is much finer than the resolving power of the data (see below) variations in the inverted viscosity profile will have a spatial scale that reflects the resolving power, not the model discretization. Inverse or forward analysis based on a much smaller number of layers (e.g., isoviscous, upper mantle, and lower mantle) may significantly misrepresent the information content of the data and lead to biased viscosity profiles (see Mitrovica [1996] for a more complete discussion of this issue).

In the inversions described below, we incorporate an additional model parameter, the thickness of the elastic lithosphere, $L$. The associated 29th element of the Fréchet kernel vector for each datum is defined by

$$
\delta \log y_{i}=F_{i}^{L}(\log v) \delta L,
$$

where $\delta L$ is a perturbation in the thickness of the elastic lithosphere. The 29th parameter thus determines the $L A B$ and the thickness of the 28th model layer.

The iteration scheme given by equation (5) will be deemed to have converged once the misfit statistic $Q\left(\hat{\mathbf{X}}_{k}\right)$ given by

$$
Q\left(\hat{\mathbf{X}}_{k}\right)=\left[\mathbf{y}-f\left(\hat{\mathbf{X}}_{k}\right)\right]^{T} \mathbf{V}_{\epsilon}^{-1}\left[\mathbf{y}-f\left(\hat{\mathbf{X}}_{k}\right)\right],
$$

falls within the $99 \%$ confidence interval of the $\chi_{N}^{2}$ distribution, where $N$ is the number of degrees of freedom. The converged solution will be defined by an a posteriori model, which we denote by $\hat{\mathbf{X}}_{\mathrm{PO}}$ and the associated covariance $\mathbf{V}_{\mathrm{PO}}$. Due to the weakly nonlinear character of this inversion, the solutions generally converge after one iteration.

\section{Data}

\subsection{Fennoscandian Relaxation Spectrum}

The FRS is derived from ancient strandlines that can be traced more or less continuously for $\sim 1000 \mathrm{~km}$ from the center of uplift out to the periphery, and that permit an estimate of the uplift rate in the region versus spatial scale. The data set, and its analysis, were pioneered by McConnell [1968], who used strandline data compiled by Sauramo [1958] to infer the radial profile of viscosity to a depth of $1200 \mathrm{~km}$. This depth is consistent with the resolving power of the data set [Parsons, 1972; Mitrovica and Peltier, 1993b]. A revised FRS spanning the degree ranges $15 \leq \ell \leq 49$ and $61 \leq \ell \leq 73$ was derived by Wieczerkowski et al. [1999], who used a set of strandline records published by Donner [e.g., Donner, 1980] that extend from near Ångerman River to southern Finland and (in a subset of the records) terminate in Estonia (see Figure 1a). Wieczerkowski et al. [1999] used a damped least squares approach that allowed for a rigorous assessment of uncertainty in the FRS, and the reader is referred to this publication for a comprehensive discussion of both their methodology and a suite of sensitivity tests related to the sampling of the strandline data and common assumptions made in forward calculations of the FRS. We adopt the FRS derived by Wieczerkowski et al. [1999], although we truncate our analysis at degree 64 (Figure 2a). This truncation has no impact on our results given the large uncertainty in the relaxation times for degrees above 60 [Wieczerkowski et al., 1999]. It does, however, decrease the shallow mantle sensitivity of the FRS data relative to the sensitivity associated with McConnell [1968] original values.

\subsection{Postglacial Decay Times}

As we noted above, and following Walcott [1972] original analysis of records from Hudson Bay, postglacial decay times have been determined by fitting an exponential form (equation (3)) through local RSL histories (sometimes termed uplift or emergence curves) at sites near the center of the now-vanished late Pleistocene ice sheets. Given their relative insensitivity to ice history, the decay times $(\lambda)$ represent an important constraint on mantle viscosity, and there have been many efforts to estimate them at sites in Hudson Bay and James Bay, Canada [e.g., Mitrovica and Peltier, 1995; Mitrovica and Forte, 1997; Peltier, 1998a; Mitrovica et al., 2000; Fang and Hager, 2002], and Ångerman River, Sweden [Mitrovica, 1996; Mitrovica and Forte, 2004; Nordman et al., 2015]. For Richmond Gulf in Hudson Bay we adopt a one sigma constraint on the decay time of 4.0-6.6 kyr [Mitrovica et al., 2000]. For James Bay, we have computed a postglacial decay time of 2.7-4.7 kyr based on a new RSL curve for the region [Pendea et al., 2010]. An earlier estimate of the James Bay decay time (2.0-2.8 kyr), based on records collected in the mid 1970s [Hardy, 1976; Mitrovica et al., 2000], was inconsistent with the Richmond 

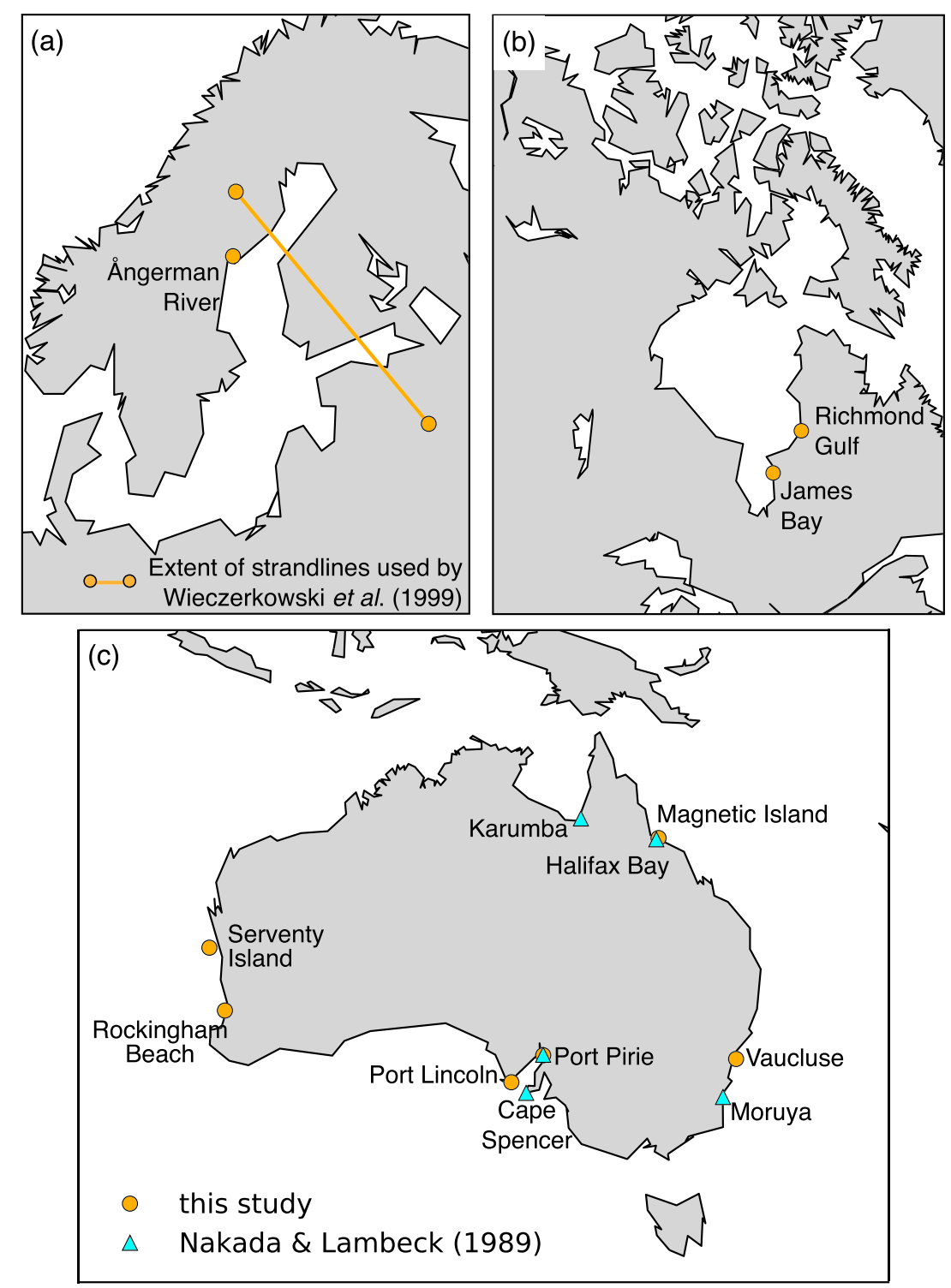

Figure 1. (a) Map of Scandinavia including the extent of strandlines used to determine the FRS [Wieczerkowski et al., 1999] and the location of Ångerman River. (b) Map of Hudson Bay showing the locations of Richmond Gulf and James Bay. (c) Location of Australian late Holocene sea level highstand records studied by Nakada and Lambeck [1989] and the more recent compilation adopted in the present study as labeled.

Gulf value, and this posed significant difficulties for viscosity inversions based upon both of them. The revised decay time is more consistent with the Richmond Gulf datum and avoids this complication. For the decay time at Ångerman River, we adopt the recent estimate of Nordman et al. [2015], 4.2-6.2 kyr, which is a minor revision to the estimate in Mitrovica and Forte [2004] (4.0-5.7 kyr). The decay times adopted in our inversions are shown in Figure 2b, and their geographical locations are shown in Figures 1a and 1b. The Mitrovica et al. [2000] analysis ensured free decay of the Hudson Bay and James Bay sites by choosing a time window for their decay time analysis of $8.5 \mathrm{kyr}$. Nordman et al. [2015] adopted a time window of $7 \mathrm{kyr}$ for their analysis of the Ångerman River decay time. Our numerical calculations of decay times adopt the same windows.

\section{3. $j_{2}$}

As noted in the section 1 , recent analyses of the $J_{2}$ time series estimated from satellite altimetry measurements since the mid-1970s indicated a significant change in trend circa 1990 [Nerem and Wahr, 2011; Roy and Peltier, 2011; Cheng et al., 2013], and the time series has been fit with, for example, a quadratic trend [Cheng et al., 2013] or with a slope break in the early 1990s [Roy and Peltier, 2011]. The change in trend that occurred $\sim 1990$ 

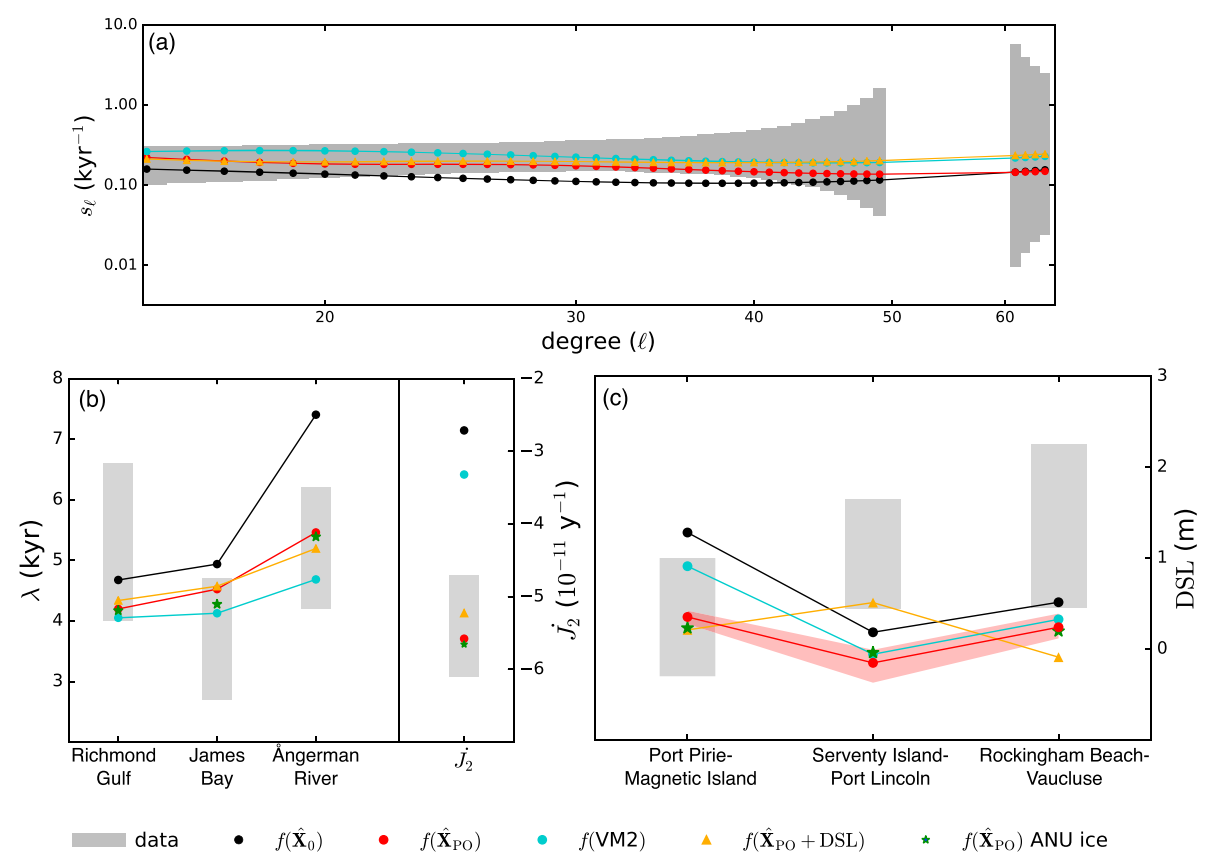

Figure 2. Observational constraints (gray bars) associated with (a) the Fennoscandian relaxation spectrum; (b) postglacial decay times in Richmond Gulf, James Bay, Ångerman River, and $j_{2}$; and (c) differential sea level highstands. Predictions based on both the starting model, $\hat{\mathbf{X}}_{0}$, and the a posteriori model in Figure $4, \hat{\mathbf{X}}_{\mathrm{PO}}$, are superimposed on each frame. The red shading in Figure $2 \mathrm{c}$ encompasses a set of predictions of the DSL highstands based upon the a posteriori viscosity model in Figure 4 and lithospheric thicknesses ranging from 87 to $107 \mathrm{~km}$. Also included in each frame are predictions based on the viscosity model VM2 [Peltier, 2004] and an additional a posteriori model, $\hat{\mathbf{X}}_{\mathrm{PO}}+\mathrm{DSL}$, discussed in section 4.2.3 in which DSL highstand data were incorporated into the inversion.

has been associated with the onset of more significant melting from polar ice sheets, and so we focus here on the altimetry record from 1976 to 1990 . Using the results of Cheng et al. [2013], we estimate a linear trend across the time window of $(-3.4 \pm 0.3) \times 10^{-11}$ years ${ }^{-11}$, where the uncertainty accounts for nonlinearity in the time series [Mitrovica et al., 2015]. Cheng et al. [2013] estimated the size of signals in the observed time series associated with atmospheric and ocean variability, and the 18.6 year tide, and using their calculations suggests that these signals may combine to produce a trend of order $0.3 \times 10^{-11}$ years ${ }^{-1}$. Accordingly, we augment the above uncertainty in the observed trend to a value of $0.5 \times 10^{-11}$ years $^{-11}$.

In order to isolate the signal from GIA (which would have remained constant over the twentieth century) in the harmonic $j_{2}$, one must correct the observed trend for contamination associated with ice melting [/vins et al., 1993; Mitrovica and Peltier, 1993a; Nakada et al., 2015a; Mitrovica et al., 2015]. Marzeion et al. [2015] recently updated glacier tabulations by Marzeion et al. [2012] and Leclercq et al. [2011] and compared these, together with release 1301 of the Cogley [2009] database. The latter two tabulations are based on direct and geodetic measurements, with suitable extrapolation to unsampled areas, while the first is based on modeled responses to local climate observations. Over the period 1976-1990, the Cogley [2009] database has a mass flux rate from all glaciers of $0.66 \pm 0.03 \mathrm{~mm} \mathrm{yr}^{-1}$ in units of equivalent global mean sea level (GMSL) rise. The analogous values for the updated Leclercq et al. [2011] database are $0.35 \pm 0.05 \mathrm{~mm} \mathrm{yr}^{-1}$ and for the updated Marzeion et al. [2012] database $0.42 \pm 0.12 \mathrm{~mm} \mathrm{yr}^{-1}$. Over the period 1971-2009, AR5 of the IPCC based its estimates of glacier mass flux on Marzeion et al. [2012] and Cogley [2009]. Following the IPCC, we focus on the Cogley [2009] and Marzeion et al. [2012] results to compute the $j_{2}$ signal for the period 1976-1990. We have calculated the total $j_{2}$ signal associated with these tabulations and they are the following: $(-1.94 \pm 0.10) \times 10^{-11}$ years ${ }^{-1}$ and $(-1.07 \pm 0.05) \times 10^{-11}$ years $^{-1}$, respectively. Combining these two estimates yields a $J_{2}$ rate of $(-1.5 \pm 0.4) \times$ $10^{-11}$ years $^{-1}$, where the uncertainty is computed from the spread of the two estimates rather than the formal uncertainties in each. (Including the Leclercq et al. [2011] time series yields a marginally different estimate of the rate, $(-1.4 \pm 0.4) \times 10^{-11}$ years $^{-1}$.)

In addition to the above source of melt, Kjeldsen and Korsgaard [2015] analyzed photographic evidence to estimate mass loss from the Greenland Ice Sheet from 1900 to 2010. Their so-called geodetic method yields 
an estimate of mass loss from 1976 to 1990 of $0.12 \pm 0.5 \mathrm{~mm} \mathrm{yr}^{-1}$ in units of GMSL. Using this inference, we have calculated a $j_{2}$ signal of $(0.5 \pm 0.2) \times 10^{-11}$ years ${ }^{-1}$ over the same period. Combining this with the glacier signal gives a total $j_{2}$ signal due to modern melt sources of $(2.0 \pm 0.5) \times 10^{-11}$ years ${ }^{-1}$. Our standard inversion described below will adopt this melt signal. Correcting the observed trend $(-3.4 \pm 0.5) \times 10^{-11}$ years ${ }^{-1}$ for this signal yields a residual signal of $(-5.4 \pm 0.7) \times 10^{-11}$ years $^{-1}$, which represents our estimate of the ongoing GIA contribution to $j_{2}$. (This value is consistent with the GIA rate inferred by Nakada et al. [2015a] and Mitrovica et al. [2015].) We will, however, consider the sensitivity of our results to the adopted melt signal by varying it over a range consistent with the above uncertainty; i.e., $(1.5-2.5) \times 10^{-11}$ years ${ }^{-1}$.

\subsection{Differential Sea Level Highstands}

We will explore the consistency of predictions based on our inverted viscosity profiles with differential sea level (DSL) highstands between various pairs of far-field sites. In the classic study of Nakada and Lambeck [1989], four DSL highstand pairs were used to infer a large increase ( 2 orders of magnitude) in mantle viscosity with depth. All sites were located in the Australasia region (see Figure 1): Karumba (Queensland), Halifax Bay (Queensland), Moruya (New South Wales), Port Pirie (South Australia), Cape Spencer (South Australia), and Christchurch (New Zealand). The late Holocene sea level record across Australia has recently been updated [e.g., Sloss et al., 2007; Lewis et al., 2013], and our analysis is based on this new set of records. We performed synthetic tests to explore the sensitivity of the predicted DSL highstands to variations in the ice model by considering forward predictions based on two ice models: ICE-6G [Peltier et al., 2015] and a global ice model developed at the Australian National University (ANU) [Fleming and Lambeck, 2004]. On this basis, we culled the DSL highstand data set to include only site pairs for which the two predictions agreed to within half of one sigma observational uncertainty. This yielded site pairs: Port Pirie-Magnetic Island (Belperio et al. [2002] and Collins et al. [2006], respectively), Serventy Island-Port Lincoln (Collins et al. [2006] and Belperio et al. [2002], respectively), and Rockingham Beach-Vaucluse [Lewis et al. [2013] and Sloss et al. [2007], respectively). (See Figure 1 for site locations.) Their associated DSL highstand values are $0.35 \pm 0.65 \mathrm{~m}, 1.04 \pm 0.45 \mathrm{~m}$, and $1.35 \pm 0.90 \mathrm{~m}$, respectively.

\section{Results and Discussion}

\subsection{Fréchet Kernels}

Fréchet kernels provide a measure of the sensitivity of a datum to depth-dependent perturbations in mantle viscosity. We explore this sensitivity in Figure 3, which shows kernels for the data sets listed in section 3, for two different viscoelastic models (see Table 1). Model A has a moderate, factor of 2 increase in viscosity from the upper mantle ( $10^{21} \mathrm{~Pa}$ s) to the lower mantle; this jump is increased to a factor of 10 in Model $B$ by reducing the upper mantle viscosity to $5 \times 10^{20} \mathrm{~Pa}$ s and increasing the lower mantle viscosity to $5 \times 10^{21} \mathrm{~Pa}$.

Figures $3 \mathrm{a}$ and $3 \mathrm{~b}$ show values of the kernel for each datum associated with a perturbation in lithospheric thickness, $L$ (i.e., $F^{L}$ in equation (8), plotted as a percent perturbation in the datum per kilometer perturbation in $L$ ). The DSL highstand data - and in particular the Serventy Island-Port Lincoln pair - exhibit the greatest sensitivity to lithospheric thickness variations, which reflects the underlying physical process that gives rise to spatial variations in the Australian RSL highstands; namely, the levering (or tilting) of the lithosphere and crust in response to ocean loading. The sensitivity is, however, a strong function of the specific pair of sites being considered. The sensitivity of the FRS data to changes in $L$ increases monotonically with increasing spherical harmonic degree, with the greatest sensitivity being a $\sim 1 \%$ reduction in the predicted inverse decay time per kilometer increase in the lithospheric thickness. Finally, the Hudson Bay and Fennoscandian decay times, as well as the $j_{2}$ datum, are insensitive to lithospheric thickness changes.

In considering the remaining Fréchet kernels, we first focus on results for Model A. The sensitivity of the FRS to variations in mantle viscosity is strongest in the upper mantle with peak sensitivities at the base of the lithosphere (the latter reflects the sensitivity associated with highest degree components of the FRS). There is a monotonic decrease in the lumped sensitivity with depth, and the relaxation spectrum is relatively insensitive to viscosity perturbations below $\sim 1000 \mathrm{~km}$. The kernel for the postglacial decay time at Ångerman River has a sensitivity that peaks in the upper mantle and extends $\sim 500 \mathrm{~km}$ into the lower mantle. In comparison, the kernels for the decay times at sites in Hudson Bay have a diminished sensitivity to the upper mantle and a sensitivity that extends further into the lower mantle. This difference in the radial range of the kernels reflects the distinct spatial scales of the ice sheets that covered the two regions [Mitrovica, 1996]. In contrast to the FRS and decay times, the sensitivity of the $\dot{J}_{2}$ datum to perturbations in mantle viscosity increases toward the 

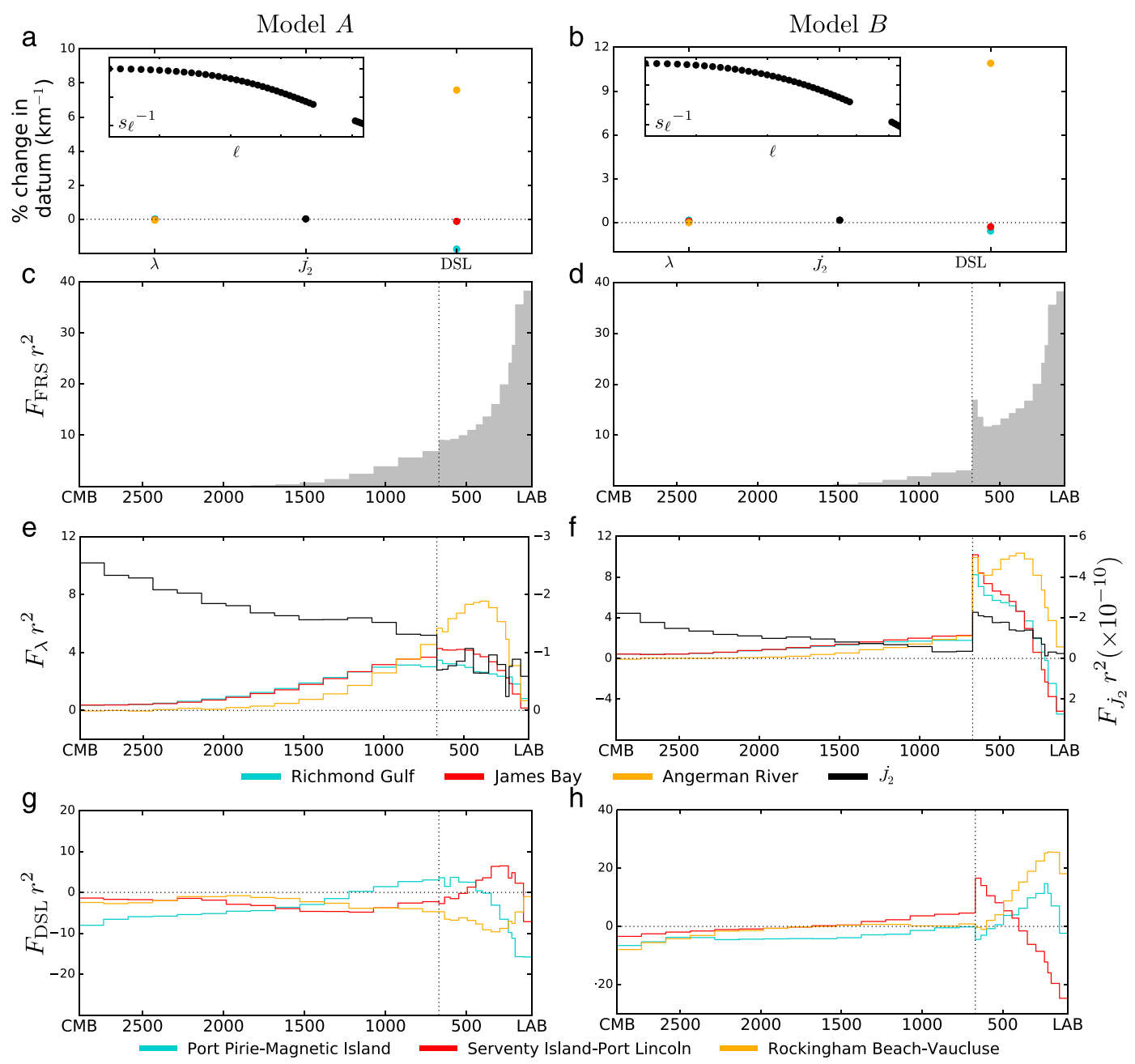

Figure 3. Dimensionless Fréchet kernels computed using Models ( $a, c, e$, and $g$ ) A and (b, $d, f$, and $h$ ) B. See Table 1 for all model parameters. Figures $3 \mathrm{a}$ and $3 \mathrm{~b}$ show the 29th value of the Fréchet kernel for each datum associated with the lithospheric thickness parameter, in units of percent change per km (equation (8)). The insets show kernel values associated with the FRS. The color circles correspond to the specific sites shown in the keys below Figures $3 \mathrm{e}-3 \mathrm{~h}$. Figures $3 \mathrm{c}-3 \mathrm{~h}$ show Fréchet kernels computed for the 28 radial viscosity parameters. (Figures $3 \mathrm{c}$ and $3 \mathrm{~d}$ ) Kernels for the FRS, where the shaded band spans the full region sampled by all kernels in the degree range $15 \leq \ell \leq 49$ and $61 \leq \ell \leq 64$. The blue line in Figure $3 \mathrm{c}$ is discussed in section 4.2.3. (Figures $3 e$ and 3f) Kernels for the logarithm of the postglacial decay times, $\log _{10} \lambda$, at Richmond Gulf (Canada), James Bay (Canada), and Ångerman River (Sweden), as well as the $j_{2}$ datum. Note that the left vertical axes in Figures $3 e$ and $3 f$ are values associated with the decay times, and the right vertical axes are associated with $j_{2}$. (Figures $3 \mathrm{~g}$ and $3 \mathrm{~h}$ ) Kernels for the DSL highstands between the following pairs of Australian sites: Goold Island-Port Hacking, Redcliff-Port Lincoln, and Serventy Island-Port Lincoln. All kernels in Figures $3 c-3 h$ are scaled by $r^{2}$. In Figures $3 c-3 h$ the horizontal axes mark depth $(\mathrm{km})$, and the black-dotted vertical line marks the boundary between the upper mantle and lower mantle.

CMB. The amplitude of the kernel decreases by 50\% across the lower mantle from the CMB to $670 \mathrm{~km}$ depth and drops abruptly at the boundary with the upper mantle. Finally, DSL highstand data each have distinct sensitivities to mantle viscosity, though all the kernels tend to show a broad sensitivity to viscosity across both the lower and upper mantle. The former results from the large spatial scale of the ocean load, while the latter reflects the sensitivity of the levering process to shallow mantle structure.

The Frećhet kernels computed using Model B, characterized by an order of magnitude viscosity jump at $670 \mathrm{~km}$ depth, show sensitivities that are shifted toward shallower depths, relative to predictions based on Model A. By introducing a higher viscosity lower mantle, flow is more confined to the upper mantle, thus increasing the upper mantle sensitivity of each datum. As a measure of this trend, Table 2 lists the integrated area under the Fréchet kernels in the upper and lower mantle for each datum (or in the case of the FRS the 
Table 1. Viscosity Models Discussed in the Text ${ }^{\mathrm{a}}$

\begin{tabular}{lccc} 
Model & Lithospheric Thickness $(\mathrm{km})$ & Upper Mantle $v(\mathrm{~Pa} \mathrm{~s})$ & Lower Mantle $v$ (Pa s) \\
\hline A & 96 & $1.0 \times 10^{21}$ & $2.0 \times 10^{21}$ \\
B & 96 & $0.5 \times 10^{21}$ & $5.0 \times 10^{21}$ \\
\hline
\end{tabular}

${ }^{\text {a } T h e ~ b o u n d a r y ~ b e t w e e n ~ t h e ~ u p p e r ~ a n d ~ l o w e r ~ m a n t l e ~ i s ~ a t ~} 670 \mathrm{~km}$ depth. Elastic and density structure is given by the seismic model PREM [Dziewonski and Anderson, 1981].

lumped kernel) and the two Earth models. The significant change in the depth range of the kernels evident in Figure 3 and Table 2 underscores the nonlinearity of the mapping between viscosity and GIA data sets.

\subsection{Bayesian Inversion for Mantle Viscosity}

We begin by presenting the results of nonlinear, Bayesian inversions (equation (5)) that adopt Model $A$ as both the starting model, $\hat{\mathbf{X}}_{0}$, and the a priori model, $\left(\mathbf{X}_{\mathrm{PR}}\right)$. We assume no prior covariance between the model parameters and adopt a prior variance, $\sigma_{\mathrm{PR}^{\prime}}^{2}$ of 20 for all log-viscosity model parameters and $100 \mathrm{~km}^{2}$ for the lithospheric thickness. The large prior variances allow the a posteriori solution to move significantly from the a priori model should the data require this. Predictions based on the a priori (and starting) model are shown in Figure 2.

Figure 4 shows the results of a joint inversion of the FRS, postglacial decay times, and $j_{2}$ data sets. The a posteriori estimate of the lithospheric thickness is $96.87 \pm 9.97 \mathrm{~km}$. The minor reduction in the uncertainty of the estimate of $L$ from its a priori value reflects the relative lack of sensitivity of these data to variations in this parameter. The inverted model is characterized by a weak asthenosphere, with a viscosity as low as $\sim 10^{20} \mathrm{~Pa} \mathrm{~s}$, an average viscosity of $\sim 10^{21} \mathrm{~Pa}$ s in the top $\sim 1000 \mathrm{~km}$ of the lower mantle, and a relatively uniform increase in viscosity to $\sim 5 \times 10^{22} \mathrm{~Pa} \mathrm{~s}$ at $2400 \mathrm{~km}$ depth. The latter is maintained to the base of the mantle. Predictions based on the inverted model are shown on Figure 2, labeled $f\left(\hat{\mathbf{X}}_{\mathrm{PO}}\right)$.

The a priori (and starting) model misfits all data used in the inversion except the postglacial decay time at Richmond Gulf and decay times in the FRS outside the degree range $21-42$. The lower viscosity of the inverted model relative to the starting model across nearly all depths from the LAB to the mid-lower mantle reduces the relaxation times at all degrees and brings the predicted FRS into accord with the observations. This reduction in viscosity also decreases the predicted postglacial decay times. In particular, the a posteriori model yields decay times that match the observed values at all three sites: Ångerman River, James Bay, and Richmond Gulf. Finally, the inverted model is characterized by a significantly higher viscosity in the deep mantle (below $\sim 1700 \mathrm{~km}$ depth) relative to the starting model, and this increases the amplitude of the predicted $\dot{j}_{2}$ anomaly by $\sim 80 \%$, sufficient to match the observation. Predictions based on the viscosity model VM2 [Peltier, 2004] are also shown in Figure 2. We note that this model yields a reasonable fit to all the data in Figures $2 \mathrm{a}$ and $2 \mathrm{~b}$ with the exception of a major misfit with the $j_{2}$ datum.

The significance of the variability and trends in the inverted viscosity profile in Figure 4 is dependent on the radial resolving power of the data set. We explore this issue in two ways. First, we compute weighted averages of the inverted model parameters, where the weightings are given by Fréchet kernels computed using the a

Table 2. Integrated Area Under the Fréchet Kernels in Figure 3 Within the Lower and Upper Mantle, Expressed as a Percentage of the Total Area

\begin{tabular}{lccccc} 
& \multicolumn{2}{c}{ Model A } & & \multicolumn{2}{c}{ Model B } \\
\cline { 2 - 3 } \cline { 6 - 6 } & Lower & Upper & & Lower & Upper \\
\hline FRS & 5 & 95 & & 2 & 98 \\
Richmond Gulf & 25 & 75 & & 16 & 84 \\
James Bay & 23 & 77 & & 18 & 92 \\
Ångerman & 12 & 88 & & 5 & 95 \\
$j_{2}$ & 56 & 44 & & 30 & 70 \\
Port Pirie-Magnetic Island & 32 & 68 & & 31 & 69 \\
Serventy Island-Port Lincoln & 38 & 62 & & 9 & 91 \\
Rockingham Beach-Vaucluse & 18 & 82 & & 9 & 91 \\
\hline
\end{tabular}



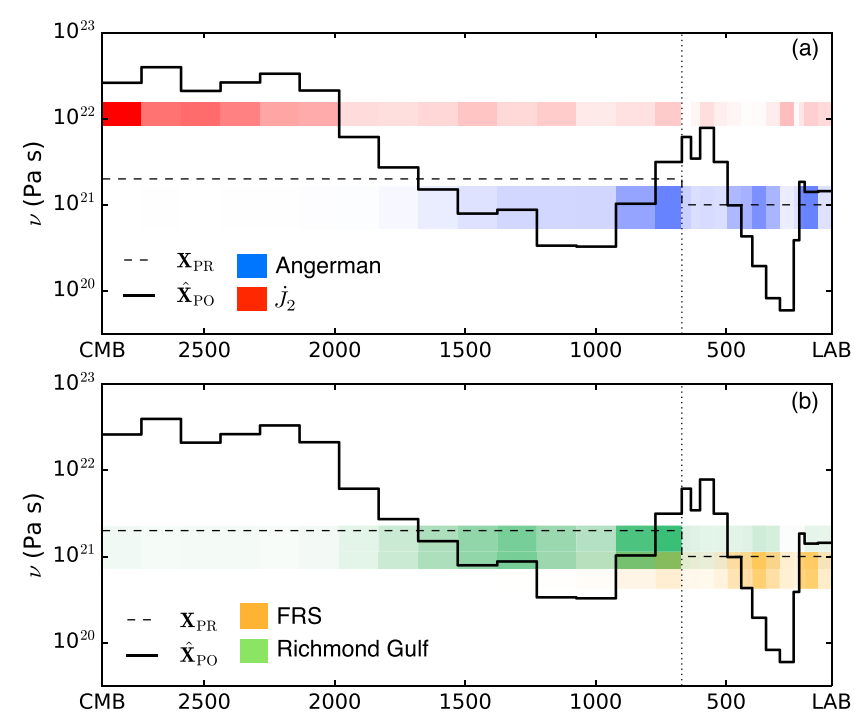

Figure 4. Nonlinear, Bayesian inversion of the FRS, postglacial decay times from (a) Richmond Gulf and James Bay, and (b) Ångerman River and $j_{2}$ observations. The dashed black line is the starting and a priori model adopted in the inversion. The solid black line is the a posteriori solution. These are repeated in Figures $4 \mathrm{a}$ and $4 \mathrm{~b}$. The height of the center of each color band denotes the weighted average $\left(\overline{\mathbf{F}}_{i}^{T} \mathbf{X}_{\mathrm{PO}}\right)$ of the inverted model, where the weightings are normalized, and volumetrically scaled Fréchet kernels for the posterior model are shown in Figure 5 (equation (10)). The vertical thickness of each color band represents the 1 standard deviation bound on the weighted average, while the color intensity indicates the normalized amplitude of the averaging kernel, $\overline{\mathbf{F}}_{i}$ (see Figure 5). In each frame the horizontal axis marks depth $(\mathrm{km})$, and the black-dotted vertical line marks the boundary between the upper mantle and lower mantle.

posteriori model (Figure 5). (In this exercise we do not include the final lithospheric thickness component of the Fréchet kernel; see equation (8)). Following equation (7), we denote the $i$ th such Fréchet kernel as $F_{i}\left(\mathbf{X}_{\mathrm{PO}}, r\right)$ and define normalized versions of these kernels that satisfy

$$
\int_{\mathrm{CMB}}^{\mathrm{LAB}} \bar{F}_{i}\left(\mathbf{X}_{\mathrm{PO}}, r\right) r^{2} \mathrm{~d} r=1,
$$

where $\bar{F}_{i}\left(\mathbf{X}_{\mathrm{PO}}, r\right)=c_{i} F_{i}\left(\mathbf{X}_{\mathrm{PO}}, r\right)$ and the constant $c_{i}$ is chosen to satisfy the normalization constraint. If we express the normalized kernel in vector form as $\overline{\mathbf{F}}_{i}$, then the $i$ th weighted average is given by

$$
\hat{X}_{i}=\overline{\mathbf{F}}_{i}^{T} \mathbf{X}_{\mathrm{PO}}
$$

which has variance

$$
\mathbf{V}_{i}=\overline{\mathbf{F}}_{i}^{T} \mathbf{V}_{\mathrm{PO}} \overline{\mathbf{F}}_{i} .
$$

The colored horizontal bars superimposed on Figures $4 \mathrm{a}$ and $4 \mathrm{~b}$ are designed to provide three pieces of information. The intensity of the shading across the bar reflects the amplitude of the normalized kernel $\bar{F}_{i}\left(\mathbf{X}_{\mathrm{PO}}, r\right)$ across the 28 layers spanning the CMB to LAB. The height at the center of the bar represents the weighted average $\overline{\mathbf{F}}_{i}^{T} \mathbf{X}_{\mathrm{PO}}$, and the vertical thickness of the bar represents 1 standard deviation uncertainty of the estimate. The four bars refer, as labeled, to weighted averages of the posterior model based on kernels for the postglacial decay times at Richmond Gulf (green) and Ångerman River (blue), the $\dot{j}_{2}$ constraint (red), and the FRS (orange; in this case, the averaging kerning kernel is denoted by the black line in Figure $5 \mathrm{a}$, which provides a representative sensitivity of the FRS to variations in mantle viscosity).

As an example, the weighted average associated with the Ångerman River decay time is $\sim 10^{21} \mathrm{~Pa}$ s. The averaging reflects a dominant sensitivity that extends to a depth of $\sim 1000 \mathrm{~km}$ (see the blue bar in Figure 4 a or the posterior Fréchet kernel for this decay time in Figure $5 \mathrm{~b}$ ). This average represents the classic constraint on mantle viscosity known as the "Haskell value" [Haskell, 1935; Mitrovica, 1996]. The weighted average resolved by the Hudson Bay decay time data is also $\sim 10^{21} \mathrm{~Pa}$; however, the averaging kernel in this case shows significantly greater sensitivity to viscosity in the top half of the lower mantle than the Ångerman River kernel (Figure 5b). The yellow bar in Figure 4 indicates that the FRS data are highly sensitive to the viscosity structure 

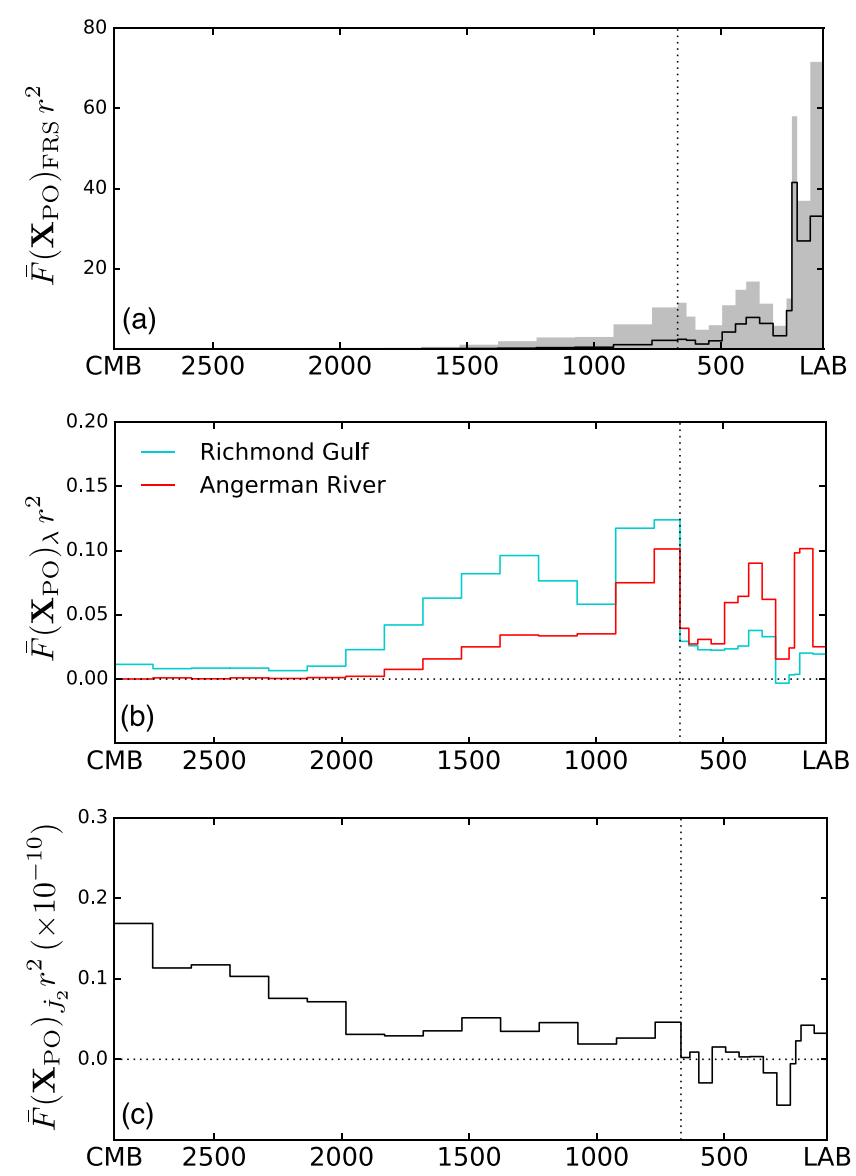

Figure 5. Fréchet kernels as defined in equation (7) for (a) the FRS; (b) postglacial decay times at Ångerman River, Sweden, and Richmond Gulf, Canada; and (c) the $j_{2}$ datum, all computed using the a posteriori model in Figure 4 (the lithospheric thickness of this model is $96.87 \mathrm{~km}$ ). The kernel for the James Bay decay time (not shown) differs negligibly from the kernel associated with the Richmond Gulf decay time. All kernels are scaled by $r^{2}$. In each frame the horizontal axis marks depth $(\mathrm{km})$, and the black-dotted vertical line marks the boundary between the upper mantle and lower mantle.

just beneath the LAB. Whereas the higher-degree components of the FRS constrain this shallow upper mantle structure, the lower degree components extend the sensitivity throughout the upper mantle and into the top $200 \mathrm{~km}$ of the lower mantle (Figure 5a).

The weighted averages in Figure 4 provide insight into the high deep mantle viscosity of the inverted model. The Hudson Bay and Ångerman River data have combined sensitivities that extend from the middle of the upper mantle to the middle of the lower mantle, and these constraints drive the mean viscosity in this region to $\sim 10^{21} \mathrm{~Pa} \mathrm{~s}$ (within the upper mantle, the inverted profile is also strongly controlled by the FRS). The $j_{2}$ datum has a sensitivity to viscosity that is nonnegligible throughout the lower mantle, and fitting it requires a weighted mean viscosity of $\sim 10^{22} \mathrm{~Pa} s$ across this region, where the weighting is dominated by values in the bottom half of the lower mantle (red bar in Figure $4 \mathrm{a}$ and kernel in Figure $5 \mathrm{c}$ ). Thus, in order to fit both the decay time data and the $j_{2}$ observation, the viscosity of the bottom half of the lower mantle in the inverted model must increase to values above $10^{22} \mathrm{~Pa}$ s. Indeed, $\mathbf{X}_{\mathrm{PO}}$ peaks at $\sim 4 \times 10^{22} \mathrm{~Pa}$ in this region, and the volumetric average of the model in the bottom $1000 \mathrm{~km}$ of the mantle is $\sim 2.5 \times 10^{22} \mathrm{~Pa} \mathrm{~s}$.

The resolving power of the inversion as a function of depth can be also explored by examining the a posteriori covariance matrix, $\mathbf{V}_{\mathrm{PO}}$, as defined in equation (6); (Figure 6). With the exception of the shallowest layers of the inverted model, the variance of the model parameters, i.e., the diagonal elements of $\mathbf{V}_{\mathrm{PO}}$ (Figure $6 \mathrm{a}$ ), show little reduction from their a priori values, and this indicates that the observations do not resolve viscosity structure on the radial length-scale of the individual model layers. As discussed in section 2.2, although ice age data are not able to resolve the viscosity across a length-scale comparable to any single model layer thickness, 


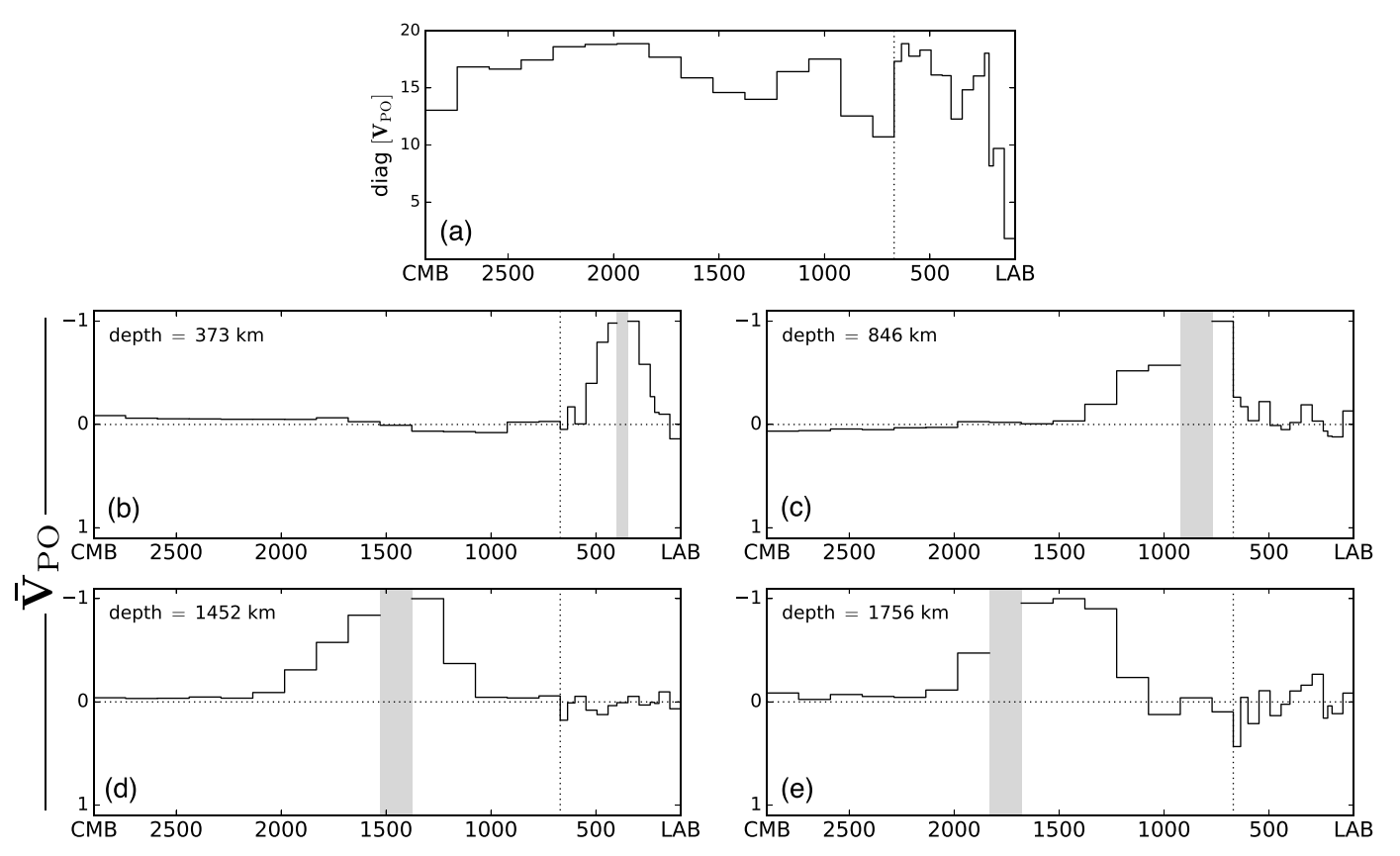

Figure 6. The posterior covariance matrix, $\mathbf{V}_{\mathrm{PO}}$ (equation (6)), for the inversion shown in Figure 4. (a) The diagonal values of $\mathbf{V}_{\mathrm{PO}}$. (b-e) Select rows of $\overline{\mathbf{V}}_{\mathrm{PO}}$ for target radii (as labeled) ranging from (Figure 6b) just below the LAB to (Figure 6e) the middle of the lower mantle. The target layer in each case is shown by gray shading that identifies its location. In all frames, the $\mathbf{V}_{\mathrm{PO}}$ values associated with the lithospheric thickness parameter are not included. The horizontal axis marks the depth $(\mathrm{km})$, and the black-dotted vertical line marks the boundary between the upper mantle and lower mantle.

we adopt this fine discretization to avoid biasing any viscosity inversion by introducing, for example, artificial viscosity jumps. The resolving power is, in this regard, more directly reflected by the rows of the covariance matrix. Figures $6 \mathrm{~b}-6 \mathrm{e}$ show a representative set of rows of $\mathbf{V}_{\mathrm{PO}}$ that span target depths in the top $1800 \mathrm{~km}$ of the mantle. The covariances in each frame are normalized such that the peak off-diagonal value is unity (the normalized posterior covariance matrix is denoted $\overline{\mathbf{V}}_{\mathrm{PO}}$ ).

For rows corresponding to model layers within the top half of the mantle (Figures $6 b-6 d$ ), the covariances are roughly centered on the target depth and the resolving power (as reflected by the spread of the covariances) decreases with depth. As an example, the estimate of viscosity at $373 \mathrm{~km}$ depth (Figure 6b) will represent an average that extends across the most of the upper mantle. This resolution decreases to $\sim 1000 \mathrm{~km}$ (420-1450 km depth) and $\sim 1400 \mathrm{~km}$ (700-2100 km depth) for targets at $846 \mathrm{~km}$ (Figure 6c) and $1452 \mathrm{~km}$ (Figure 6d) depth. Finally, covariances associated with estimates of viscosity at depths greater than the middle of the lower mantle (e.g., Figure 6e) peak in layers at shallower depths (i.e., the covariances are no longer centered on the target depth), and this reflects the limited ability of the data set to resolve structure at these depths.

\subsubsection{Sensitivity Analyses}

In a first series of sensitivity tests, we adopted the same prior and starting model discussed above but included only one data type (FRS, $j_{2}$, or decay times) in each inversion (Figure 7). The goal in these tests is to further refine our understanding of the constraints that each data subset contributes to the joint inversion in Figure 4.

An inversion of the FRS data alone departs from the a priori model in the top $800 \mathrm{~km}$ of the mantle, and it closely tracks the a posteriori model generated from the inversion of the full data set in the upper mantle above the transition zone. The latter indicates that much of the finer-scale upper mantle structure of the inverted model in Figure 4 is controlled by the constraints imposed by the FRS. The decay time inversion yields a model characterized by a mean viscosity of $\sim 5 \times 10^{20} \mathrm{~Pa}$ s in the upper mantle below the LAB and an increase to $\sim 3 \times 10^{21} \mathrm{~Pa}$ s across the top $600 \mathrm{~km}$ of the lower mantle. This trend satisfies the Haskell constraint on mantle viscosity discussed above [Haskell, 1935; Mitrovica, 1996]. Below this depth and toward the $\mathrm{CMB}$, the viscosity values tend toward the a priori model, reflecting the progressively decreasing depth sensitivity of these data. Finally, an inversion of the $j_{2}$ constraint alone yields an a posteriori model that tracks the 


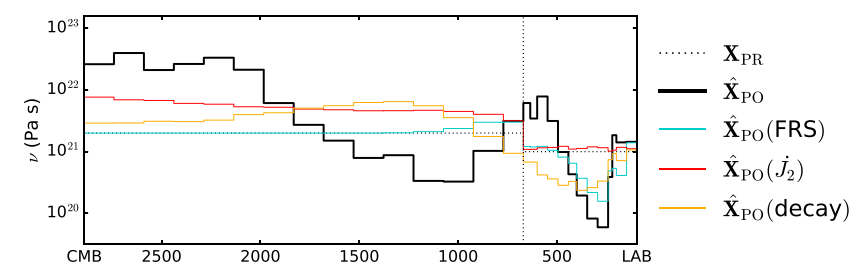

Figure 7. Results from sensitivity testing of the nonlinear, Bayesian inversion: $\hat{\mathbf{X}}_{\mathrm{PO}}$ and $\mathbf{X}_{\mathrm{PR}}$ are reproduced from Figure 4. $\hat{\mathbf{X}}_{\mathrm{PO}}$ (FRS) is the posterior model for an inversion that included only the Fennoscandian relaxation spectrum, $\hat{\mathbf{X}}_{\mathrm{PO}}\left(j_{2}\right)$ included only the $j_{2}$ datum and $\hat{\mathbf{X}}_{\mathrm{PO}}$ (decay) included only the three postglacial decay times. The horizontal axis marks the depth $(\mathrm{km})$, and the black-dotted vertical line marks the boundary between the upper mantle and lower mantle.

a priori model in the upper mantle and increases to values of $\sim 10^{22} \mathrm{~Pa}$ s near the base of the lower mantle. This is consistent with our earlier observation that the datum has relatively little sensitivity to upper mantle viscosity and a broad sensitivity to lower mantle viscosity that constrains the mean viscosity in this region to be $\sim 10^{22} \mathrm{~Pa} s$ in the bottom half of this region. This result emphasizes once again that the $j_{2}$ datum provides the dominant constraint on deep mantle viscosity in our inversions; without this constraint the information content of the GIA data would largely end at mid-lower mantle depths.

The information content of each data subset can be quantified by considering the trace of the so-called resolution matrix [Backus, 1988]:

$$
\mathbf{R}=\mathbf{I}-\mathbf{V}_{\mathrm{PO}} \mathbf{V}_{\mathrm{PR}}^{-1}
$$

where $\mathbf{I}$ is the identity matrix. The trace of $\mathbf{R}, \operatorname{tr}[\mathbf{R}]$, is a measure of the number of independent parameters resolvable in a given inversion, and it is listed in Table 3 for the four a posteriori models shown in Figure 7. If the data provided perfect resolution in any inversion, then $\operatorname{tr}[\mathbf{R}]$ would be equal to the number of parameters (in our case 29). The fact that the sum of the $\operatorname{tr}[\mathbf{R}]$ computed for inversions with single-data types is approximately equal to the trace when all data types are included indicates that the data subsets do not have significant overlap in information content.

Next, we explore the impact on the inversions when applying smoothing to the model parameters. To include smoothing in the inversion, we introduce covariances in the matrix $\mathbf{V}_{\mathrm{PR}}$. Specifically, the element on the $m$ th row and $n$th column of the matrix can be expressed as

$$
\left[V_{\mathrm{PR}}\right]_{m n}=\sigma(m) \sigma(n) e^{-\left\|r_{m}-r_{n}\right\| \gamma^{-1}} \text {. }
$$

Here $\sigma(m)$ is the prior standard deviation of the $m$ th model parameter, $r_{m}$ is the center radius of that parameter, and the extent of smoothing is controlled by the correlation length-scale $\gamma$. Figure 8a shows an inversion where $\gamma=1000 \mathrm{~km}$. For reference, we include $\mathbf{X}_{\mathrm{PO}}$ from Figure 4 in which $\gamma=0 \mathrm{~km}$. Note that covariances are confined to the 28 log-viscosity parameters and no smoothing is applied across the $670 \mathrm{~km}$ discontinuity. Not surprisingly, oscillations in the inverted model for this case are damped relative to the $\gamma=0 \mathrm{~km}$ case; in particular the asthenospheric viscosity is not as low. Note also that the inverted model has no viscosity jump at $670 \mathrm{~km}$ depth, suggesting that the data do not require a viscosity discontinuity at this depth. The inverted model fits all data sets included in the inversion; as an example, the fit to the FRS is shown in Figure 8b. Next, we add some covariance to the 39 FRS data points by updating entries of $\mathbf{V}_{\varepsilon}$ associated with the FRS as follows:

$$
\left[V_{\varepsilon}\right]_{m n}=\sigma(m) \sigma(n) e^{-\|\ell(m)-\ell(n)\| \varepsilon^{-1}}
$$

where the extent of smoothing is controlled by $\varepsilon$ and $\ell(m)$ is the spherical harmonic degree associated with data point $m$. Figure 8 a shows an inversion where we adopt $\varepsilon=10$. Introducing a correlation between the FRS effectively downweights the importance of the FRS in the inversion, and this leads to a somewhat degraded fit of the model to these data. Specifically, the asthenospheric viscosity dip is suppressed resulting in predictions of the FRS (where $21 \leq \ell \leq 42$ ) that are too low. The fits to the decay time and $j_{2}$ rate are unaffected since these data do not resolve structure on this spatial scale (see Figure 4).

Next, we explore the impact on the inversions of changing the a priori and starting models. Figure 9 reproduces the model in Figure 4, which was derived from an inversion using Model A of Table 1 as both the prior and starting model. The figure also shows the results of three further inversions in which Model $B$ replaced Model A as the prior model (cyan line) or starting model (orange line). The red line represents an inversion 
Table 3. Trace of Resolution Matrix for Inversions Based on Various Data Subsets

\begin{tabular}{lc} 
Test & $\operatorname{tr}[\mathbf{R}]$ \\
\hline$\hat{\mathbf{X}}_{\mathrm{PO}}$ & 6.75 \\
$\hat{\mathbf{X}}_{\mathrm{PO}}($ FRS $)$ & 4.03 \\
$\hat{\mathbf{X}}_{\mathrm{PO}}\left(j_{2}\right)$ & 0.99 \\
$\hat{\mathbf{X}}_{\mathrm{PO}}$ (decay) & 2.36 \\
\hline
\end{tabular}

where both the prior and starting models are Model B. The prior covariance matrix is unaltered from the case in Figure 4; that is, the variance values are unchanged, and no smoothing is incorporated into the inversions. Changing the prior model has little impact on the inversion, and thus, in the nomenclature of Bayesian inverse theory, the prior models adopted here are noninformative.

In contrast, changing the starting model does impact the inversion, particularly in the lower mantle: just beneath the $670 \mathrm{~km}$ discontinuity the inversions adopting Model $B$ as a starting model (red and orange lines) dip to viscosities of $\sim 10^{20}$ Pa $s$ but are followed by a more rapid rise in viscosity deeper into the mantle. The viscosity values plateau at $\sim 2 \times 10^{22}$ Pa s below $1900 \mathrm{~km}$ depth. As we have noted, a comparison of inverted profiles should not be based on a layer-by-layer comparison of model values but rather should be based on averages that reflect the resolving power of the data. To this end, Figure 9 shows two weighted averages of the posterior model $\left(\mathbf{F}_{i}^{T} \mathbf{X}_{\mathrm{PO}}\right)$ for the inversion where Model $\mathrm{B}$ is adopted as both the starting and prior model, where the weightings reflect Fréchet kernels of the posterior model associated with the Richmond Gulf decay times (green) and $\dot{J}_{2}$ datum (red). These averages are consistent with analogous averages computed for the inversion where Model $A$ is adopted as the starting and prior model (Figure 4). We conclude that the inversion is insensitive to the starting model when one accounts for the resolving power of the data.

We have argued that the data sets adopted in our inversions are relatively insensitive to details of the ice history. To investigate this issue, Figure 2 includes a set of forward predictions based on the ANU global ice reconstructions [Fleming and Lambeck, 2004] (green stars). This ice history is paired with the a posteriori viscosity model of Figure 4 that was derived via an inversion that adopted the ICE- 6 G history. Discrepancies between the forward predictions of $j_{2}$, postglacial decay times, and DSL highstands based on these ice histories are small compared to the uncertainties in the data, confirming that these data sets are relatively insensitive to details of the ice history. (We note, by definition, that the FRS is identical for both as this is a property of the posterior model alone.)

Finally, we also explore the sensitivity of our a posteriori model to the correction applied to the observed $j_{2}$ signal to account for modern glacier and ice sheet melt over the period 1976-1990. As we have discussed,
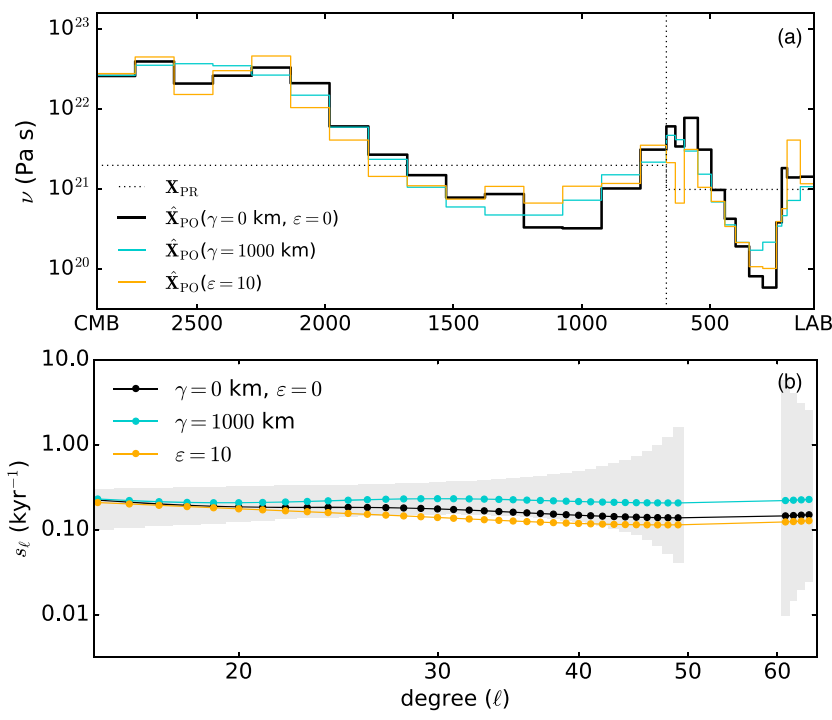

Figure 8. (a) Posterior models from nonlinear, Bayesian inversions where smoothing is included in the log-viscosity model parameters $(\gamma=1000 \mathrm{~km}$; see equation (14)) or covariances are introduced between the FRS data $(\varepsilon=10$; see equation (15)). For comparison, we reproduce the posterior model from Figure 4 which adopted $\gamma=0 \mathrm{~km}$ and $\varepsilon=0$. The horizontal axis marks the depth $(\mathrm{km})$, and the black-dotted vertical line marks the boundary between the upper mantle and lower mantle. (b) Predictions of the FRS using the posterior models from Figure 8a. 


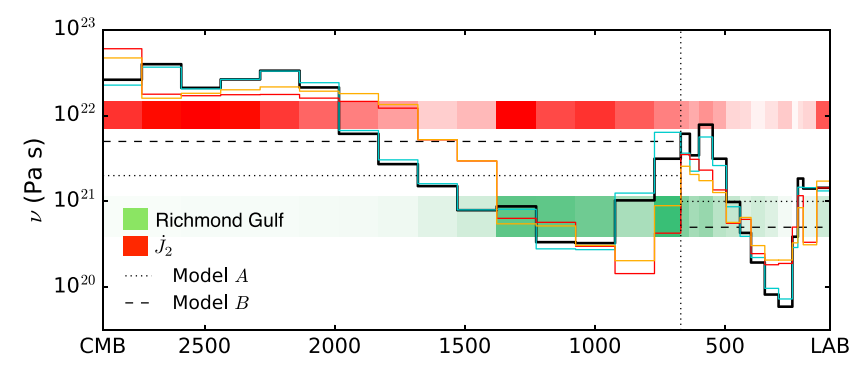

Figure 9. Nonlinear, Bayesian inversions adopting various starting and prior viscosity models. The black line reproduces the inversion in Figure 4 which adopted Model $A$ as the prior and starting model. The cyan and orange lines repeat this inversion with the exception that Model B (Table 1) is adopted as either the prior or starting model, respectively. The red line is the result of an inversion where Model $B$ is both the starting and prior model. The color bands are weighted averages $\left(\overline{\mathbf{F}}_{i}^{T} \mathbf{X}_{\mathrm{PO}}\right.$; equation (11)) of the inverted model (red line), where the weightings are normalized and volumetrically scaled posterior Fréchet kernels for Richmond Gulf and $j_{2}$. The horizontal axis marks the depth $(\mathrm{km})$, and the black-dotted vertical line marks the boundary between the upper mantle and lower mantle.

the $j_{2}$ rate we estimated from Cheng et al. [2013] was $(-3.4 \pm 0.5) \times 10^{-11}$ years ${ }^{-1}$, and the correction for modern melt used in our previous inversions was $(2.0 \pm 0.5) \times 10^{-11}$ years ${ }^{-1}$. In Figure 10 we explore the impact on the a posteriori viscosity model of using modern melt corrections of $1.5 \times 10^{-11}$ years ${ }^{-1}$ and $2.5 \times 10^{-11}$ years ${ }^{-1}$. In the three inversions shown on the figure, the peak viscosity in the lower mantle varies from $\sim 2 \times 10^{22} \mathrm{~Pa}$ s to $\sim 6 \times 10^{22} \mathrm{~Pa}$ s across this range of corrections. The mean viscosity across the bottom $1000 \mathrm{~km}$ of the mantle varies from $1.7 \times 10^{22} \mathrm{~Pa}$ s to $3.8 \times 10^{22} \mathrm{~Pa}$ s. We conclude that uncertainty in the melt correction maps into an uncertainty of a factor or $\sim 2$ in the mean viscosity of the deep mantle, and above this depth the sensitivity is negligible.

\subsubsection{Viscosity Structure Within the Lower Mantle}

The combination of decay time data, which constrain the average viscosity from the middle of the upper mantle to the top $500 \mathrm{~km}$ (Angerman River) and $1200 \mathrm{~km}$ (Richmond Gulf and James Bay) of the lower mantle to be $\sim 10^{21} \mathrm{~Pa} \mathrm{~s}$, and the $j_{2}$ datum, which requires a mean viscosity in the bottom half of the lower mantle of $\sim 10^{22} \mathrm{~Pa}$ s, drive inversions with a robust requirement for a significant increase of viscosity, with depth, in the lower mantle. This increase is consistent with inferences based on a joint inversion of GIA data and mantle convection observables [Mitrovica and Forte, 1997, 2004], which show a 2 order of magnitude increase in viscosity from $670 \mathrm{~km}$ depth to the deep lower mantle. However, neither of these earlier inversions included the $j_{2}$ datum, and the inference of a high-viscosity deep mantle (and lower viscosity $D^{\prime \prime}$ region) was, in those studies, driven by constraints associated with a set of convection-related observations.

Important early viscous flow modeling of mantle convection observables demonstrated that a viscosity jump in the shallow lower mantle provided a better fit to observational constraints on the long-wavelength nonhydrostatic geoid, plate motions, and CMB topography than a jump at the $670 \mathrm{~km}$ boundary between the upper and lower mantle [Forte, 1987; Forte et al., 1991]. This suggestion was supported by a joint inversion of mantle convection and GIA observables [Mitrovica and Forte, 1997] and also by seismic evidence suggesting a boundary at $920 \mathrm{~km}$ depth [Kawakatsu and Niu, 1994]. Several recent studies have revisited the issue

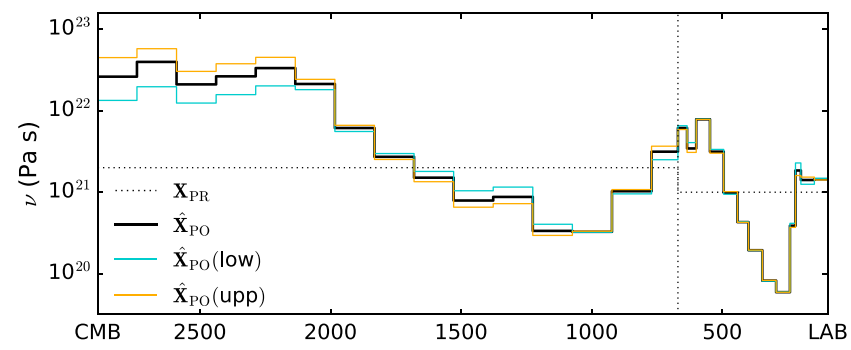

Figure 10. Nonlinear, Bayesian inversions repeating the calculation in Figure 4 (black line) but applying a different modern melt correction to the $j_{2}$ datum. $\mathbf{X}_{\mathrm{PO}}$ (lower) and $\mathbf{X}_{\mathrm{PO}}$ (upper) denote the posterior solutions associated with melt corrections of $1.5 \times 10^{-11}$ years ${ }^{-1}$ and $2.5 \times 10^{-11}$ years $^{-1}$, respectively. The horizontal axis marks the depth $(\mathrm{km})$ and the black-dotted vertical line marks the boundary between the upper mantle and lower mantle. 

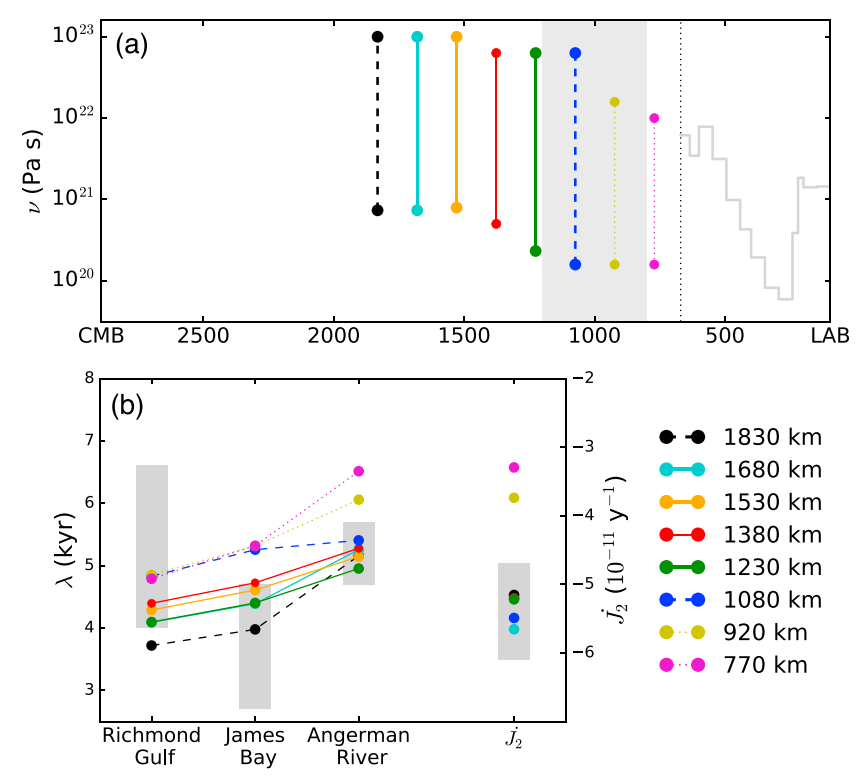

Figure 11. Results from a suite of 800 forward calculations distinguished on the basis of the adopted Earth model. In all calculations the upper mantle viscosity was fixed to the value obtained in the inversion shown in Figure 4 (and shown here as a gray line with layering). The lower mantle was discretized into two layers. The free parameters of the modeling were (1) the location of the viscosity boundary in the lower mantle and (2) the viscosities in layers above and below this boundary (see text). (a) Vertical lines summarize the best fitting model for each of eight boundary locations (see legend at bottom right). The horizontal position of the line indicates the depth of the boundary, the upper bound and lower bound on each line provide the viscosity below and above the boundary, respectively, for the best fit model. Model results have been culled to include only those that fit the FRS observation. The data used in the misfit calculation includes the postglacial decay times at Richmond Gulf and James Bay, and Ångerman River and $j_{2}$. The horizontal axis marks the depth $(\mathrm{km})$, and the black-dotted vertical line marks the boundary between the upper mantle and lower mantle. (b) The predictions of the decay time data and $j_{2}$ for the best fit models are summarized in Figure $11 \mathrm{a}$. In both frames, best fit models that yielded predictions that satisfied all the decay time constraints and the $j_{2}$ datum are denoted by solid lines, and those that misfit one or more of these constraints are denoted by dashed and dotted lines, respectively.

using a variety of data sets, and they have added to the case for a viscosity jump at $\sim 1000 \mathrm{~km}$ depth [Ballmer et al., 2015; Rudolph et al., 2015]. The ice age data sets adopted in the present study are unable to resolve a sharp viscosity boundary at such depths, although it is possible from our results that such a boundary is not inconsistent with the constraints imposed by these data sets.

To explore this issue, we set up a large suite of forward calculations in which the upper mantle is prescribed to have the structure given by the inverted model in Figure 4, and the lower mantle is discretized into two isoviscous layers. The boundary between these two lower mantle layers is systematically varied over a depth range of $770-1830 \mathrm{~km}$, and for each location we consider a range of viscosity values above $(1.6-50) \times 10^{20} \mathrm{~Pa} \mathrm{~s}$ and below $(1.6-100) \times 10^{21} \mathrm{~Pa}$ s the boundary. We do not assume that the lower layer is more viscous than the upper layer. A total of 800 simulations were performed. We first culled from this set of simulations all models in which the predicted FRS did not fit the observational constraint; this was a relatively small number (43) since the FRS data are dominantly sensitive to upper mantle structure (Figures 3 and 5), which was not varied. Next, for each depth of the boundary between the two lower mantle regions we determined the best fitting pair of viscosity values above and below the boundary. The results of this Monte Carlo analysis are summarized in Figure 11.

The vertical lines in Figure 11a represent the best fit solutions when the lower mantle viscosity boundary is placed at the specified depth. The extreme values on each line provide the viscosity above and below the boundary that define this best fit model. (All best fit models are characterized by a more viscous lower layer relative to the upper layer within the lower mantle.) The vertical lines are drawn as solid when the best fit model satisfies all observational constraints, dashed when all but one decay time is fit and dotted when more than one observation is misfit. Accordingly, the data sets can all be satisfied when the viscosity boundary is placed between $\sim 1200$ and $1700 \mathrm{~km}$ depth. (The gray shading on the figure covers the depth range $800-1200 \mathrm{~km}$, 


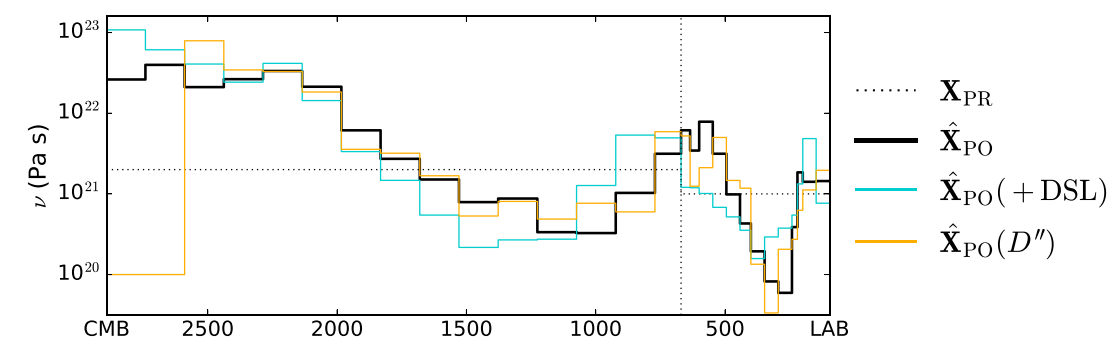

Figure 12. Results of several nonlinear, Bayesian inversions: $\hat{\mathbf{X}}_{\mathrm{PO}}$ is reproduced from Figure $4 . \hat{\mathbf{X}}_{\mathrm{PO}}(+\mathrm{DSL})$ is the posterior model for an inversion identical to Figure 4 except that the data set is augmented to include the three DSL observations shown in Figure 2. $\hat{\mathbf{X}}_{\mathrm{PO}}\left(D^{\prime \prime}\right)$ is the result of an inversion identical to Figure 4 except that the viscosity values in the two layers extending $300 \mathrm{~km}$ above the $\mathrm{CMB}$ are fixed to $10^{20} \mathrm{~Pa}$ s. The black-dotted line is the starting and a priori model adopted in both inversions (Model A from Table 1). The horizontal axis marks the depth (km), and the black-dotted vertical line marks the boundary between the upper mantle and lower mantle.

where previous studies cited above have inferred viscosity jumps.) The preferred viscosity in the upper layer of the lower mantle increases from $(2.3$ to 7.4$) \times 10^{20} \mathrm{~Pa}$ as the boundary is moved from $1200 \mathrm{~km}$ to $1700 \mathrm{~km}$ depth, and the viscosity jump across the boundary, which is $\sim 2$ orders of magnitude, is required to fit the $j_{2}$ datum. We note that the preferred range of depths for the viscosity boundary placed within the lower mantle is limited by the small number of free parameters in the suite of models considered in Figure 11. Allowing the upper mantle viscosity to vary in the modeling, or adding more layers in the lower mantle, will broaden the range of depths where a sharp boundary can be introduced while preserving a fit to the observations.

Various lines of evidence suggest that the viscosity of the $D^{\prime \prime}$ region at the base of the mantle will be relatively low, including, e.g., ab initio methods [e.g., Ammann et al., 2010], geodetic observations [Nakada and Karato, 2012], and previous joint inversions of GIA and mantle convection data sets [Mitrovica and Forte, 2004]. We explored this issue by repeating the inversion in Figure 4 but imposing a viscosity of $10^{20} \mathrm{~Pa} s$ in the mantle region extending up to $300 \mathrm{~km}$ above the $\mathrm{CMB}$ (this region corresponds to the deepest two layers of the discretized viscosity model). The a posteriori model in this case (orange line in Figure 12) exhibits only minor differences from the original inversion, reinforcing our earlier argument that the data used in the inversion have limited resolving power in the deepest mantle (see Figure 6h). This conclusion is in accord with the GIA analyses of Nakada et al. [2015a, 2015b].

4.2.3. Consistency With DSL Highstands

DSL highstand data have played an important role in inferences of mantle viscosity based on GIA data [Nakada and Lambeck, 1989]. The inversions discussed above did not include the DSL highstand data summarized in section 3.4. To investigate the consistency of the DSL highstand data to our earlier inversion, Figure 2c shows predictions of the DSL highstand data computed using the viscosity profile in Figure 4 (red line). The shading superimposed on this line encompasses a range of predictions obtained by running a series of forward calculations in which we varied the lithospheric thickness across the $1 \sigma$ range inferred from this original inversion (i.e., (87 $\leq L \leq 107) \mathrm{km}$ ) while keeping the viscosity profile unchanged. This posterior solution is able to provide a fit to the Port Pirie-Magnetic Island datum but misfits the other two DSL highstand data.

We next repeated the inversion of Figure 4 with a data set that was augmented to explicitly include the three DSL highstand pairs. The only other change from the inversion in Figure 4 is that we increased the prior standard deviation of the lithospheric thickness parameter to $50 \mathrm{~km}$. The resulting viscosity profile is shown in Figure 12 (labeled $\hat{\mathbf{X}}_{\mathrm{PO}}(+\mathrm{DSL})$ ), and the posterior estimate for $L$ is $(130 \pm 50) \mathrm{km}$. The inverted profile in Figure 12 shows the same trends as the original $\hat{\mathbf{X}}_{\mathrm{PO}}$; however, in comparison to this earlier inversion, the lithospheric thickness is significantly larger.

The posterior predictions based on $\hat{\mathbf{X}}_{\mathrm{PO}}(+\mathrm{DSL})$ are shown in Figure 2 (orange triangles). The inverted model fits all data sets with the exception of the Rockingham Beach-Vaucluse DSL highstand pair. This result reveals an inconsistency that can be illustrated by considering the Serventy Island-Port Lincoln and the Rockingham Beach-Vaucluse pairs and their dominant sensitivity to variations in the lithospheric thickness. The predictions for these two pairs based on the starting model (black circles in Figure 2) underpredict the observational data. Their associated Fréchet kernels (red and yellow circles in Figure 3, respectively) indicate that an increase in $L$ will produce changes in the predictions for each DSL highstand pair of opposing sign. Thus, perturbation in 
the starting value of the lithospheric thickness cannot yield a simultaneous fit to both DSL pairs. This inconsistency may reflect lateral variations in lithospheric thickness or mantle viscosity or an underestimation of the observational uncertainties.

\section{Conclusions}

Inferring the radial profile of mantle viscosity from the analysis of data sets related to glacial isostatic adjustment is a problem in geophysical research that extends back nearly a century, to the pioneering work of Daly [1925] and Haskell [1935]. However, despite some consensus that GIA data sets are compatible with - and indeed prefer - a 1-D viscosity profile that increases by several orders of magnitude with depth from the base of the lithosphere to CMB [McConnell, 1968; Nakada and Lambeck, 1989; Mitrovica, 1996; Lambeck et al., 1998; Mitrovica and Forte, 2004], two recent viscosity profiles inferred in the literature [Argus et al., 2014; Lambeck et al., 2014; Nakada et al., 2015a] appear to be irreconcilable. In particular, whereas Lambeck et al. [2014] and Nakada et al. [2015a] advocate for a viscosity profile that increases from 1 to $2 \times 10^{20} \mathrm{~Pa}$ s in the upper mantle to $\sim 7 \times 10^{22} \mathrm{~Pa}$ s in the lower mantle, the VM5a model of Argus et al. [2014] is characterized by a significantly more muted increase, from $5 \times 10^{20} \mathrm{~Pa} s$ at the $L A B$ to $3 \times 10^{21} \mathrm{~Pa}$ s above the CMB. Both models place their viscosity jump (or at least the bulk of this increase) at $670 \mathrm{~km}$ depth.

We have revisited the 1-D viscosity problem, and addressed this recent debate, by analyzing GIA data using a combination of forward predictions and inversions based on nonlinear Bayesian inference. Inferences of mantle viscosity based on observations related to GIA are complicated by uncertainties in the space-time history of ice cover since the Last Glacial Maximum, and to avoid (or at least minimize) this issue, we have focused our analysis on parameterizations of these data sets that reduce the sensitivity to ice history. These data sets include site-specific, postglacial decay times inferred from relative sea level records in Hudson Bay and Sweden [e.g., Walcott, 1972; Mitrovica et al., 2000; Fang and Hager, 2002; Nordman et al., 2015], the Fennoscandian relaxation spectrum [e.g., Sauramo, 1958; McConnell, 1968; Wieczerkowski et al., 1999], differential sea level highstands from the Australian region [e.g., Nakada and Lambeck, 1989; Kaufmann and Lambeck, 2002], and the rate of change of the degree 2 zonal harmonic of the Earth's geopotential or $j_{2}$ [e.g., Cheng et al., 2013]. Subsets of these data have been used in a number of previous viscosity inferences based on forward analyses and formal inversions [Mitrovica and Peltier, 1993a; Mitrovica, 1996; Kaufmann and Lambeck, 2002; Mitrovica and Forte, 2004; Peltier, 2004], but no study has simultaneously included all these data sets in a joint inversion for the mantle viscosity profile. Our overarching goal has been to address the robustness of these recent, seemingly incompatible inferences of the 1-D mantle viscosity profile by analyzing these data sets within a rigorous inverse formalism.

On the basis of our inversions, we conclude that mantle viscosity increases by at least 2 orders of magnitude with depth from the LAB to CMB. This inference (Figure 4 ) is driven by a sequence of correlated constraints. In particular: the FRS constrains the mean upper mantle viscosity to a value of $\sim 3 \times 10^{20} \mathrm{~Pa}$ s; the Fennoscandian and Hudson Bay postglacial decay times constrain the mean value of viscosity from the mid-upper mantle to mid-lower mantle to be $\sim 10^{21} \mathrm{~Pa}$ s, a requirement that encompasses the classic Haskell constraint on mantle viscosity [Haskell, 1935; Mitrovica, 1996]; and, finally, the $\dot{J}_{2}$ datum constrains the mean viscosity in the bottom half of the lower mantle to be $\sim 10^{22} \mathrm{~Pa}$ s. Taken together, these constraints yield a viscosity in the lower mantle that peaks at $\sim 10^{23} \mathrm{~Pa} \mathrm{~s}$ (with a mean value in excess of $10^{22} \mathrm{~Pa} \mathrm{~s}$ ). We have demonstrated that this overall trend in mantle viscosity with depth is robust relative to the choice of starting and prior models adopted in the inversions.

Our inference is consistent with previous estimates of mantle viscosity based on GIA data sets [Nakada and Lambeck, 1989; Mitrovica, 1996; Lambeck et al., 1998; Kaufmann and Lambeck, 2002; Lambeck et al., 2014; Nakada et al., 2015a], but we emphasize three important issues. First, our constraint on mantle viscosity in the bottom half of the mantle is dominated by the pre-1990 trend in the $\dot{J}_{2}$ datum, an observable that has been corrected for the signal due to contemporaneous melting from glaciers [Vaughan et al., 2013]. If this correction is robust, the $\dot{J}_{2}$ datum rules out a broad suite of studies that have inferred a deep mantle viscosity only moderately higher than $10^{21}$ Pa s [Peltier, 2004; Argus et al., 2014; Peltier et al., 2015]. A similar conclusion was reached by Nakada et al. [2015a] and Mitrovica et al. [2015] using forward predictions of the $j_{2}$ datum. Second, our inversions indicate that the GIA data sets we have considered can be reconciled by a mantle viscosity profile without a viscosity jump at $670 \mathrm{~km}$ depth. The GIA data do not have the resolving power to infer such a sharp increase, and previous inferences for a jump in viscosity at this depth are generally biased by coarse 
Acknowledgments

Lau acknowledges support provided by the National Science Foundation Division of Ocean Sciences grant OCE-0825293 "PLIOMAX", the

Cooperative Studies of The Earth's Deep Interior grant EAR-1464024, and Harvard University. The authors thank Graham Cogley for discussions related to recent mountain glacier mass flux tabulations and two anonymous reviewers for their constructive comments on the original manuscript. The data for this paper are available by contacting the corresponding author at harrietlau@fas.harvard.edu. discretizations in which the upper and lower mantle are treated as isoviscous. A related issue was raised by Mitrovica [1996], who showed that two-layer (upper and lower mantle) parameterizations, combined with an incorrect assumption that the Haskell [1935] constraint on mantle viscosity resolved mean upper mantle structure, biased many previous inferences toward isoviscous mantle models. Finally, although the high deep mantle viscosity inferred in this study is dependent on the veracity of the $\dot{j}_{2}$ constraint, we note that the trend toward values of $\sim 10^{23} \mathrm{~Pa} s$ in Figure 4 is consistent with results from joint inversions of GIA (not including the $j_{2}$ datum) and mantle convection data sets [Forte and Mitrovica, 1996; Mitrovica and Forte, 1997; , 2004]. In these studies the latter data set provides the necessary deep mantle resolving power.

As we have discussed, a series of studies have suggested the possibility of a significant jump in viscosity in the shallow lower mantle [Forte, 1987; Forte et al., 1991; Mitrovica and Forte, 1997; Marquardt and Miyagi, 2015; Ballmer et al., 2015; Rudolph et al., 2015]. As with the $670 \mathrm{~km}$ discontinuity, we cannot robustly argue for the existence of such a jump. However, we have explored this issue by presenting a large suite of forward calculations that varied the depth of such a boundary, as well as the viscosity above and below the boundary, and comparing the results to the FRS, decay time, and $\dot{j}_{2}$ data. We conclude that these data are able to accommodate a viscosity jump of $\sim 2$ orders of magnitude at depths between 1000 and $1700 \mathrm{~km}$.

Finally, our inversions of the GIA data sets described above have adopted Earth models in which mantle viscosity varies with depth alone. Although we have found that most of the data sets described in section 3 can be reconciled with a 1-D mantle viscosity structure, our inability to simultaneously fit all DSL highstand data suggests that the possibility that lateral variations in mantle viscosity may be playing a role in one, or indeed all, of the GIA data sets we have considered here. In a companion article we extend the present analysis to investigate the potential bias in inferences of a 1-D mantle viscosity profile introduced by the presence of 3-D viscosity structure. The analysis will include, as an important subset, the GIA data considered here, but it will also consider an extensive global database of relative sea level histories adopted in previous GIA-based inferences of the radial profile of mantle viscosity.

\section{References}

Ammann, M. W., J. P. Brodholt, J. Wookey, and D. P. Dobson (2010), First-principles constraints on diffusion in lower-mantle minerals and a weak $D^{\prime \prime}$ layer, Nature, 465(7297), 462-465, doi:10.1038/nature09052.

Argus, D. F., W. R. Peltier, R. Drummond, and A. W. Moore (2014), The Antarctica component of postglacial rebound model ICE-6G_C (VM5a) based on GPS positioning, exposure age dating of ice thicknesses, and relative sea level histories, Geophys. J. Int., 198(1), 537-563, doi:10.1093/gji/ggu140.

Backus, G. E. (1988), Bayesian inference in geomagnetism, Geophys. J. Int., 92(1), 125-142, doi:10.1111/j.1365-246X.1988.tb01127.x.

Ballmer, M. D., N. C. Schmerr, T. Nakagawa, and J. Ritsema (2015), Compositional mantle layering revealed by slab stagnation at $\sim 1000-\mathrm{km}$ depth, Sci. Adv., 1(11), e1500,815, doi:10.1126/sciadv.1500815.

Belperio, A., N. Harvey, and R. Bourman (2002), Spatial and temporal variability in the Holocene sea-level record of the South Australian coastline, Sediment. Geol., 150(1-2), 153-169, doi:10.1016/S0037-0738(01)00273-1.

Cathles, L. M. (1975), Viscosity of the Earth's mantle, 9.

Cheng, M., B. D. Tapley, and J. C. Ries (2013), Deceleration in the Earth's oblateness, J. Geophys. Res. Solid Earth, 118(2), 740-747, doi:10.1002/jgrb.50058.

Cogley, J. G. (2009), Geodetic and direct mass-balance measurements: Comparison and joint analysis, Ann. Glaciol., 50(50), 96-100.

Collins, L. B., J.-X. Zhao, and H. Freeman (2006), A high-precision record of mid-late Holocene sea-level events from emergent coral pavements in the Houtman Abrolhos Islands, Southwest Australia, Quat. Int., 145-146, 78-85, doi:10.1016/j.quaint.2005.07.006.

Daly, R. A. (1925), Pleistocene changes of level, American Journal of Science, s5-10(58), 281 -313, doi:10.2475/ajs.s5-10.58.281.

Donner, J. (1980), The Determination and Dating of Synchronous Late Quaternary Shorelines in Fennoscandia, John Wiley, New York.

Dziewonski, A. M., and D. L. Anderson (1981), Preliminary reference Earth model, Phys. Earth Planet. Inter., 25(4), 297-356, doi:10.1016/0031-9201(81)90046-7.

Fang, M., and B. H. Hager (2002), On the apparent exponential relaxation curves at the central regions of the last Pleistocene ice sheets, in Ice Sheets, Sea Level and the Dynamic Earth, edited by J. X. Mitrovica and B. L. A. Vermeersen, pp. 201-218, AGU, Washington, D. C.

Fleming, K., and K. Lambeck (2004), Constraints on the Greenland Ice Sheet since the Last Glacial Maximum from sea-level observations and glacial-rebound models, Quat. Sci. Rev., 23(9), 1053-1077, doi:10.1016/j.quascirev.2003.11.001.

Forte, A. (1987), Plate tectonics and a spherical structure: The importance of poloidal-toroidal coupling, J. Geophys. Res., 92, 3645-3679.

Forte, A. M., and J. X. Mitrovica (1996), New inferences of mantle viscosity from joint inversion of long-wavelength mantle convection and post-glacial rebound data, Geophys. Res. Lett., 23(10), 1147-1150, doi:10.1029/96GL00964.

Forte, A. M., W. R. Peltier, and A. M. Dziewonski (1991), Inferences of mantle viscosity from tectonic plate velocities, Geophys. Res. Lett., 18(9), 1747-1750, doi:10.1029/91GL01726.

Hager, B. H., and M. A. Richards (1989), Long-wavelength variations in Earth's geoid: Physical models and dynamical implications, Philos. Trans. R. Soc. London, Ser. A, 328(1599), 309-327, doi:10.1098/rsta.1989.0038.

Hardy, L. (1976), Contribution à l'étude géomorphologique de la portion québécoise des basses terres de la baie de James, Phd dissertation, McGill Univ., Montréal, Que.

Haskell, N. A. (1935), The motion of a viscous fluid under a surface load, Physics, 6(8), 265-269, doi:10.1063/1.1745329.

Ivins, E. R., C. G. Sammis, and C. F. Yoder (1993), Deep mantle viscous structure with prior estimate and satellite constraint, J. Geophys. Res., 98(B3), 4579-4609, doi:10.1029/92JB02728. 
Kaufmann, G., and K. Lambeck (2002), Glacial isostatic adjustment and the radial viscosity profile from inverse modeling, J. Geophys. Res., 107(B11), 2280, doi:10.1029/2001JB000941.

Kawakatsu, H., and F. Niu (1994), Seismic evidence for a 920-km discontinuity in the mantle, Nature, 371(6495), 301-305, doi:10.1038/371301a0.

Kendall, R. A., and J. X. Mitrovica (2007), Radial resolving power of far-field differential sea-level highstands in the inference of mantle viscosity, Geophys. J. Int., 171, 881-889, doi:10.1111/j.1365-246X.2007.03546.x.

Kendall, R. A., J. X. Mitrovica, and G. A. Milne (2005), On post-glacial sea level-II. Numerical formulation and comparative results on spherically symmetric models, J. Geophys. Res., 161(3), 679-706, doi:10.1111/j.1365-246X.2005.02553.x.

King, S. D., and G. Masters (1992), An inversion for radial viscosity structure using seismic tomography, Geophys. Res. Lett., 19(15), 1551-1554, doi:10.1029/92GL01700.

Kjeldsen, K., and N. Korsgaard (2015), Spatial and temporal distribution of mass loss from the Greenland Ice Sheet since AD 1900, Nature, 528(7582), 396-400, doi:10.1038/nature16183.

Lambeck, K., C. Smither, and P. Johnston (1998), Sea-level change, glacial rebound and mantle viscosity for northern Europe, J. Geophys. Res., 134(1), 102-144, doi:10.1046/j.1365-246x.1998.00541.x.

Lambeck, K., A. Purcell, and A. Dutton (2012), The anatomy of interglacial sea levels: The relationship between sea levels and ice volumes during the last interglacial, Earth Planet. Sci. Lett., 315-316, 4-11, doi:10.1016/j.epsl.2011.08.026.

Lambeck, K., H. Rouby, A. Purcell, Y. Sun, and M. Sambridge (2014), Sea level and global ice volumes from the Last Glacial Maximum to the Holocene, in Proceedings of the National Academy of Sciences of the United States of America, vol. 111, pp. 15,296-15,303, doi:10.1073/pnas.1411762111.

Leclercq, P. W., J. Oerlemans, and J. G. Cogley (2011), Estimating the glacier contribution to sea-level rise for the period 1800-2005, Surv. Geophys., 32(4-5), 519-535, doi:10.1007/s10712-011-9121-7.

Lewis, S. E., C. R. Sloss, C. V. Murray-Wallace, C. D. Woodroffe, and S. G. Smithers (2013), Post-glacial sea-level changes around the Australian margin: A review, Quat. Sci. Rev., 74, 115-138, doi:10.1016/j.quascirev.2012.09.006.

Marquardt, H., and L. Miyagi (2015), Slab stagnation in the shallow lower mantle linked to an increase in mantle viscosity, Nat. Geosci., 8(4), 311-314, doi:10.1038/ngeo2393.

Marzeion, B., A. H. Jarosch, and M. Hofer (2012), Past and future sea-level change from the surface mass balance of glaciers, The Cryosphere, 6(6), 1295-1322, doi:10.5194/tc-6-1295-2012.

Marzeion, B., P. W. Leclercq, J. G. Cogley, and A. H. Jarosch (2015), Brief Communication: Global reconstructions of glacier mass change during the 20th century are consistent, The Cryosphere, 9(6), 2399-2404, doi:10.5194/tc-9-2399-2015.

McConnell, R. K. (1968), Viscosity of the mantle from relaxation time spectra of isostatic adjustment, J. Geophys. Res., 73(22), 7089-7105, doi:10.1029/JB073i022p07089.

Mitrovica, J., and A. Forte (2004), A new inference of mantle viscosity based upon joint inversion of convection and glacial isostatic adjustment data, Earth Planet. Sci. Lett., 225(1-2), 177-189, doi:10.1016/j.epsl.2004.06.005.

Mitrovica, J., C. Hay, E. Morrow, R. Kopp, M. Dumberry, and S. Stanley (2015), Reconciling past changes in Earth rotation with 20th century global sea-level rise: Resolving Munk's enigma, Sci. Adv., 1(11), E1500679, doi:10.1126/sciadv.1500679.

Mitrovica, J. X. (1996), Haskell [1935] revisited, J. Geophys. Res., 101, 555-569, doi:10.1029/95JB03208.

Mitrovica, J. X., and A. M. Forte (1997), Radial profile of mantle viscosity: Results from the joint inversion of convection and postglacial rebound observables, J. Geophys. Res., 102(B2), 2751-2769, doi:10.1029/96JB03175.

Mitrovica, J. X., and G. A. Milne (2003), On post-glacial sea level: I. General theory, J. Geophys. Res., 154(2), 253-267, doi:10.1046/j.1365-246X.2003.01942.x.

Mitrovica, J. X., and W. R. Peltier (1989), Pleistocene deglaciation and the global gravity field, J. Geophys. Res., 94(B10), 13,651-13671, doi:10.1029/JB094iB10p13651.

Mitrovica, J. X., and W. R. Peltier (1991), On postglacial geoid subsidence over the equatorial oceans, J. Geophys. Res., 96(B12), 20,053-20,071, doi:10.1029/91JB01284.

Mitrovica, J. X., and W. R. Peltier (1993a), Present-day secular variations in the zonal harmonics of Earth's geopotential, J. Geophys. Res., 98(B3), 4509-4526, doi:10.1029/92JB02700.

Mitrovica, J. X., and W. R. Peltier (1993b), The inference of mantle viscosity from an inversion of the Fennoscandian relaxation spectrum, J. Geophys. Res., 114(1), 45-62, doi:10.1111/j.1365-246X.1993.tb01465.x.

Mitrovica, J. X., and W. R. Peltier (1995), Constraints on mantle viscosity based upon the inversion of post-glacial uplift data from the Hudson Bay region, J. Geophys. Res., 122(2), 353-377, doi:10.1111/j.1365-246X.1995.tb07002.x.

Mitrovica, J. X., A. M. Forte, and M. Simons (2000), A reappraisal of postglacial decay times from Richmond Gulf and James Bay, Canada, J. Geophys. Res., 142(3), 783-800, doi:10.1046/j.1365-246x.2000.00199.x.

Morrow, E., J. X. Mitrovica, M. G. Sterenborg, and C. Harig (2013), A test of recent inferences of net polar ice mass balance based on long-wavelength gravity, J. Clim., 26(17), 6535-6540, doi:10.1175/JCLI-D-13-00078.1.

Nakada, M., and S.-I. Karato (2012), Low viscosity of the bottom of the Earth' mantle inferred from the analysis of Chandler wobble and tidal deformation, Phys. Earth Planet. Inter., 192-193, 68-80, doi:10.1016/j.pepi.2011.10.001.

Nakada, M., and K. Lambeck (1989), Late Pleistocene and Holocene sea-level change in the Australian region and mantle rheology, J. Geophys. Res., 96(3), 497-517, doi:10.1111/j.1365-246X.1989.tb06010.x.

Nakada, M., J. Okuno, K. Lambeck, and A. Purcell (2015a), Viscosity structure of Earth's mantle inferred from rotational variations due to GIA process and recent melting events, Geophys. J. Int., 202(2), 976-992, doi:10.1093/gji/ggv198.

Nakada, M., J. Okuno, and Y. Yokoyama (2015b), Total meltwater volume since the Last Glacial Maximum and viscosity structure of Earth's mantle inferred from relative sea level changes at Barbados and Bonaparte Gulf and GIA-induced $j_{2}$, Geophys. J. Int., 204(2), 1237-1253, doi:10.1093/gji/ggv520.

Nerem, R., and J. Wahr (2011), Recent changes in the Earth's oblateness driven by greenland and antarctic ice mass loss, Geophys. Res. Lett., 38, L13501, doi:10.1029/2011GL047879.

Nordman, M., G. Milne, and L. Tarasov (2015), Reappraisal of the Angerman River decay time estimate and its application to determine uncertainty in Earth viscosity structure, Geophys. J. Int., 201(2), 811-822, doi:10.1093/gji/ggv051.

O'Connell, R. J. (1971), Pleistocene glaciation and the viscosity of the lower mantle, J. Geophys. Res., 23(3), 299-327, doi:10.1111/j.1365-246X.1971.tb01823.x.

Parsons, B. (1972), Changes in the Earth's shape, PhD thesis, Univ. of Cambridge.

Peltier, W. (2004), Global glacial isostasy and the surface of the ice-age Earth: The ICE-5G (VM2) model and GRACE, Annu. Rev. Earth Planet. Sci., 32(1), 111-149, doi:10.1146/annurev.earth.32.082503.144359.

Peltier, W. R. (1974), The impulse response of a Maxwell Earth, Rev. Geophys., 12(4), 649-669, doi:10.1029/RG012i004p00649. 
Peltier, W. R. (1976), Glacial-isostatic adjustment-II. The inverse problem, Geophys. J. R. Astron. Soc., 46(3), 669-705, doi:10.1111/j.1365-246X.1976.tb01253.x.

Peltier, W. R. (1985), The LAGEOS constraint on deep mantle viscosity: Results from a new normal mode method for the inversion of viscoelastic relaxation spectra, J. Geophys. Res., 90(B11), 9411-9421, doi:10.1029/JB090iB11p09411.

Peltier, W. R. (1988), Global sea level and Earth rotation, Science, 240(4854), 895-901, doi:10.1126/science.240.4854.895.

Peltier, W. R. (1998a), The inverse problem for mantle viscosity, Inverse Prob., 14(3), 441-478, doi:10.1088/0266-5611/14/3/006.

Peltier, W. R. (1998b), A space geodetic target for mantle viscosity discrimination: Horizontal motions induced by glacial isostatic adjustment, Geophys. Res. Lett., 25(4), 543-546, doi:10.1029/98GL00182.

Peltier, W. R., R. A. Drummond, and A. M. Tushingham (1986), Post-glacial rebound and transient lower mantle rheology, J. Geophys. Res., 87(1), 79-116, doi:10.1111/j.1365-246X.1986.tb04548.x.

Peltier, W. R., D. F. Argus, and R. Drummond (2014), Postglacial Rebound Model ICE-6G_C (VM5a) Constrained by Geodetic and Geologic, Abstract G44A-08 presented at 2014 Fall Meeting, San Francisco, Calif.

Peltier, W. R., D. F. Argus, and R. Drummond (2015), Space geodesy constrains ice age terminal deglaciation: The global ICE-6G_C (VM5a) model, J. Geophys. Res. Solid Earth, 120(1), 450-487, doi:10.1002/2014JB011176.

Pendea, I. F., A. Costopoulos, C. Nielsen, and G. L. Chmura (2010), A new shoreline displacement model for the last 7 ka from eastern James Bay, Canada, Quat. Res., 73(3), 474-484, doi:10.1016/j.yqres.2010.02.001.

Ricard, Y., L. Fleitout, and C. Froidevaux (1984), Geoid heights and lithospheric stresses for a dynamic Earth, Ann. Geophys., 2, $267-285$.

Richards, M. A., and B. H. Hager (1984), Geoid anomalies in a dynamic Earth, J. Geophys. Res., 89(B7), 5987-6002, doi:10.1029/JB089iB07p05987.

Roy, K., and W. Peltier (2011), Grace era secular trends in earth rotation parameters: A global scale impact of the global warming process?, Geophys. Res. Lett., 38, L10306, doi:10.1029/2011GL047282.

Rubincam, D. P. (1984), Postglacial rebound observed by LAGEOS and the effective viscosity of the lower mantle, J. Geophys. Res., 89(B2), 1077-1088, doi:10.1029/JB089iB02p01077.

Rudolph, M. L., V. Lekić, and C. Lithgow-Bertelloni (2015), Viscosity jump in Earth's mid-mantle., Science, 350(6266), 1349-52, doi:10.1126/science.aad1929.

Sabadini, R., D. A. Yuen, and P. Gasperini (1985), The effects of transient rheology on the interpretation of lower mantle viscosity, Geophys. Res. Lett., 12(6), 361-364, doi:10.1029/GL012i006p00361.

Sabadini, R., D. A. Yuen, and P. Gasperini (1988), Mantle rheology and satellite signatures from present-day glacial forcings, J. Geophys. Res., 93(B1), 437-447, doi:10.1029/JB093iB01p00437.

Sauramo, M. (1958), Die Geschichte Der Ostsee, Acta Geogr, Helsinki.

Sloss, C. R., C. V. Murray-Wallace, and B. G. Jones (2007), Holocene sea-level change on the southeast coast of Australia: A review, The Holocene, 17(7), 999-1014, doi:10.1177/0959683607082415.

Tarantola, A., and B. Valette (1982), Generalized nonlinear inverse problems solved using the least squares criterion, Rev. Geophys., 20(2), 219-232, doi:10.1029/RG020i002p00219.

Tushingham, A. M., and W. R. Peltier (1992), Validation of the ICE-3G Model of Würm-Wisconsin deglaciation using a global data base of relative sea level histories, J. Geophys. Res., 97(B3), 3285-3304, doi:10.1029/91JB02176.

Vaughan, D., et al. (2013), Observations: Cryosphere, in Climate Change 2013: The Physical Science Basis. Contribution of Working Group I to the Fifth Assessment Report of the Intergovernmental Panel on Climate Change, vol. 4, edited by T. Stocker et al., pp. 317-382, Cambridge Univ. Press, U. K., and New York, doi:10.1017/CBO9781107415324.012.

Vermeersen, L. L. A., R. Sabadini, R. Devoti, V. Luceri, P. Rutigliano, C. Sciarretta, and G. Bianco (1998), Mantle viscosity inferences from joint inversions of pleistocene deglaciatio-induced changes in geopotential with a new SLR analysis and polar wander, Geophys. Res. Lett., 25(23), 4261-4264, doi:10.1029/1998GL900150.

Walcott, R. (1972), Late quaternary vertical movements in eastern North America: Quantitative evidence of glacio-isostatic rebound, Rev. Geophys., 10, 849-884.

Wieczerkowski, K., J. X. Mitrovica, and D. Wolf (1999), A revised relaxation-time spectrum for Fennoscandia, J. Geophys. Res., 139(1), 69-86, doi:10.1046/j.1365-246X.1999.00924.x.

Wu, P. (1978), The response of a Maxwell Earth to applied surface mass loads: Glacial isostatic adjustment, Master's thesis, Univ. of Toronto. Wu, P., and W. Peltier (1983), Glacial isostatic adjustment and the free air gravity anomaly as a constraint on deep mantle viscosity, Geophys. J. R. Astron. Soc., 74, 377-449, doi:10.1111/j.1365-246X.1983.tb01884.x.

Wu, P., and W. R. Peltier (1984), Pleistocene deglaciation and the Earth's rotation: A new analysis, J. Geophys. Res., 76(3), 753-791, doi:10.1111/j.1365-246X.1984.tb01920.x.

Yoder, C. F., J. G. Williams, J. O. Dickey, B. E. Schutz, R. J. Eanes, and B. D. Tapley (1983), Secular variation of Earth's gravitational harmonic $J_{2}$ coefficient from Lageos and nontidal acceleration of Earth rotation, Nature, 303(5920), 757-762, doi:10.1038/303757a0.

Yuen, D. A., and R. Sabadini (1985), Viscosity stratification of the lower mantle as inferred by the $J_{2}$ observation, Ann. Geophys., 3(5), 647-654. 